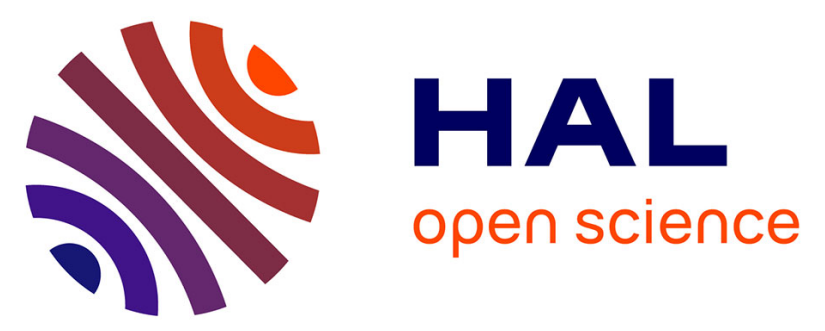

\title{
S16 and T18 mannosylation sites of LppX are not essential for its activity in phthiocerol dimycocerosates localization at the surface of Mycobacterium tuberculosis
}

Cécile Labarre, Nathalie Dautin, Anna Grzegorzewicz, Mary Jackson, Michael Mcneil, Niloofar Mohiman, Laila Sago, Nicolas Bayan

\section{To cite this version:}

Cécile Labarre, Nathalie Dautin, Anna Grzegorzewicz, Mary Jackson, Michael Mcneil, et al.. S16 and T18 mannosylation sites of LppX are not essential for its activity in phthiocerol dimycocerosates localization at the surface of Mycobacterium tuberculosis. Research in Microbiology, In press, 10.1016/j.resmic.2021.103874 . hal-03389123

\section{HAL Id: hal-03389123 https://hal.science/hal-03389123}

Submitted on 20 Oct 2021

HAL is a multi-disciplinary open access archive for the deposit and dissemination of scientific research documents, whether they are published or not. The documents may come from teaching and research institutions in France or abroad, or from public or private research centers.
L'archive ouverte pluridisciplinaire $\mathbf{H A L}$, est destinée au dépôt et à la diffusion de documents scientifiques de niveau recherche, publiés ou non, émanant des établissements d'enseignement et de recherche français ou étrangers, des laboratoires publics ou privés. 
$1 \mathrm{~S}_{16}$ and $\mathrm{T}_{18}$ mannosylation sites of LppX are not essential for its activity in

2 phthiocerol dimycocerosates localization at the surface of Mycobacterium

3 tuberculosis

4 Authors : Cécile Labarre ${ }^{a *}$, Nathalie Dautin ${ }^{a, b}$, Anna Grzegorzewicz ${ }^{c}$, Mary Jacksonc, Michael

5 McNeil $^{c}$, Niloofar Mohiman ${ }^{\mathrm{a}, \mathrm{d}}$, Laila Sago ${ }^{\mathrm{a}}$, Nicolas Bayan ${ }^{\mathrm{a}}$.

$6{ }^{a}$ Institute for Integrative Biology of the Cell (I2BC), CEA, CNRS, Univ. Paris-Sud, Universite Paris-

7 Saclay, 91198 Gif-sur-Yvette cedex, France.

8 b Present address : Laboratoire de Biologie Physico-Chimique des Protéines Membranaires,

9 Université de Paris, LBPC-PM, CNRS, UMR7099, 75005 Paris, France.

${ }^{c}$ Mycobacteria Research Laboratories, Department of Microbiology, Immunology and Pathology,

11 Colorado State University, Colorado, Fort Collins, USA.

${ }^{d}$ present address : Innovagen AB, Ideon Science Park, SE-22370 Lund, Sweden.

cecile.labarre@i2bc.paris-saclay.fr “correspondence and reprints"

14 dautin@ibpc.fr

Anna.Grezegorzewic@colostate.edu

Mary.Jackson@ColoState.EDU

17 M.Mcneil@ColoState.EDU

18 "Niloofar Mohiman" <nm@innovagen.com>

laila.sago@i2bc.paris-saclay.fr 
LppX is an important virulence factor essential for surface localization of phthiocerol dimycocerosates (DIM) in Mycobacterium tuberculosis. Based on Concanavalin A recognition, M. tuberculosis LppX (LppX-tb) was initially proposed to be glycosylated in M. tuberculosis and more recently this glycosylation was characterized by mass spectrometry analysis on LppX-tb expressed and purified from Corynebacterium glutamicum. Here, using this model organism and Mycobacterium smegmatis, we show that S16 and T18 residues of LppX-tb are indeed glycosylated with several hexoses units. Interestingly this glycosylation is strictly dependent on the mannosyl transferase PMT which, in M. tuberculosis, has been reported to be crucial for virulence. Using a site directed mutagenesis approach, we were able to show that the absence of S16 and T18 glycosylation does not alter phthiocerol dimycocerosates (DIM) localization in M. tuberculosis-

Keywords : Corynebacterium glutamicum, Mycobacterium, glycosylation, phthiocerol dimycocerosates 
Among post-translational modifications of proteins, glycosylation is the most common modification occurring in nature. These modifications which were initially thought to be restricted to eukaryotic cells are now better characterized and known to be widely distributed in bacteria and archaea. All these organisms share similar $\mathrm{N}$-glycosylation and $\mathrm{O}$-glycosylation process. While $\mathrm{N}$-glycosylation corresponds to the addition of glycosyl residues on asparagine, O-glycosylation targets serine, threonine or tyrosine. A large variety of glycans (differing in chain length, type of ose, chemical bonds and/or chemical modifications) might be added and thus creating a vast repertoire of modifications contributing to protein diversity $[1,2]$.

In eukaryotes numerous functions have been assigned to protein glycosylation such as protein folding and stability, targeting to distinct cellular compartments and cell to cell recognition [2]. Glycans can affect protein stability and accessibility as well as enable specific interaction. Moreover the nature of the glycan is important as protein dynamics differs depending on glycan chemistry [3]. As an example Prates et al. [3] studied the role of $\alpha$ mannosylation of a fungal Intrinsically Disordered Protein (IDP) by comparing different glycosylated variants of its linker. Compared to the other tested glycans, $\alpha$-mannose was shown to increase proteolytic resistance, restrict protein flexibility and lead to more extended conformations of this linker. According to the authors this would explain why, in fungi and yeast, most of the secreted IDP and proteins exhibiting Intrinsically Disordered Regions (IDR) are $\boldsymbol{O}$-mannosylated. In bacteria, the specific need for $\alpha$-mannose in such structure does not seem essential since their intrinsic high content of proline favors extended conformation of IDR. Still, elongation and further stiffening are observed upon glycosylation of these structures [3]. 
In recent years there has been a growing interest towards glycosylation in bacteria.

Although glycosylation is not restricted to pathogenic bacteria, most studies were performed in these bacteria and conclude to an important role of glycosylation on pathogenicity [1]. Indeed, this phenomenon was described in Mycobacterium tuberculosis [4] where the authors demonstrated that disruption of the $M$. tuberculosis Rv1002c gene encoding the membraneassociated protein O-mannosyl transferase (PMT) resulted in strong attenuation of the strain. In M. tuberculosis, PMT is unique and shown to be responsible for the transfer of mannose residues from polyprenol monophosphate mannose (PPM) to dedicated proteins [5]. In fact, various putatively mannosylated proteins were identified in $M$. tuberculosis by Concanavalin A affinity capture experiments [6]. Several lipoproteins including lipoproteins belonging to the LIp family (Lipid binding lipoprotein) were identified among these proteins including LppX-tb. The gene encoding LppX-tb was initially identified in a transposition mutant of $M$. tuberculosis with an attenuated phenotype [7]. In this mutant, the subcellular distribution of phthiocerol dimycocerosates (DIM) was highly altered as compared to the wild type strain. DIMs are one of the major lipidic virulence factor in pathogenic mycobacteria and their translocation at the surface of the bacterial envelope, essential for the virulence of the strain, is proposed to be mediated by LppX-tb. This hypothesis is quite convincingly corroborated by the structure of LppX-tb which ressemble a U-shaped $\beta$-half-barrel delimitating a large hydrophobic cavity able to accommodate a DIM molecule [7]. Although supposed to be glycosylated, the complete characterization of LppX-tb modifications has not been so far reported. Indeed, glycosylation of LppX-tb was previously reported during heterologous expression in slow and fast-growing mycobacteria $M$. smegmatis, $M$. bovis and $M$. abscessus [8-10]. In M. smegmatis glycosylation was only suggested and not demonstrated. Whereas further results were reported for the two other species for which 1 to 2 hexoses were found associated to the N- 
terminal peptide of the protein. However the exact glycosylation site(s) was/were never reported. Similar results have been reported in Corynebacterium glutamicum, a model host in which LppX-tb was found to be heterogeneously glycosylated with 1 to 4 hexose(s) units in its $\mathrm{N}$-terminal peptide $\left(\mathrm{aa}_{6}\right.$ to $\mathrm{aa}_{29}$ ) and where $\alpha$-mannosidase deglycosylation experiments suggested that LppX-tb is indeed mannosylated [11]. Interestingly LppX-tb glycosylation was found to be differently affected by mutations in the lipoprotein post-translational modification pathway in C. glutamicum $[11,12]$. These results enabled the authors to propose that the $\mathrm{N}$-acylation enzyme Lnt associates with PMT but that acylation (S-and N-acylation) is not a prerequisite for glycosylation of LppX-tb in C. glutamicum.

As mannosylated LppX-tb is engaged in the virulence process of $M$. tuberculosis we wondered if the attenuation phenotype observed in the PMT mutant [4] resulted from the absence of glycosylation of LppX-tb. For this, we first identified S16 and T18 as the two sites of LppX-tb mannosylation. We then undertook the construction of a variant where both amino acids were modified in order to test the functionality of this LppX-tb variant. Both the glycosylated and non-glycosylated forms of LppX-tb were characterized and found associated to the capsule layer of $M$. smegmatis. In $M$. tuberculosis Mt103, complementation of the knock-out mutant of $L p p X-t b$ either with a wild or mutated copy of the $L p p X-t b$ gene fully restored the release of DIM into the culture medium suggesting that glycosylation of S16 and T18 of LppX-tb is not necessary for DIM translocation. 


\section{Materials and methods}

104

105

106

107

108

109

110

111

112

113

114

115

116

117

\subsection{Bacterial strains and growth conditions}

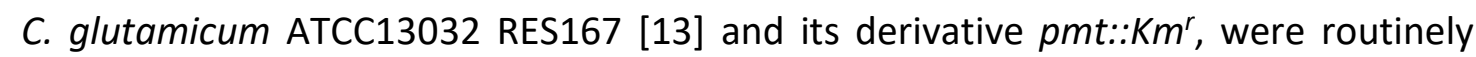
cultured on $\mathrm{BHI}$ medium (Difco) at $30^{\circ} \mathrm{C}$.

Mycobacterium smegmatis $\mathrm{MC}^{2} 155$ and Mycobacterium tuberculosis Mt103 were grown in Middlebrook 7H9 broth (Fluka) supplemented with Middlebrook ADC enrichment and $0.5 \%$ glycerol or $\mathrm{BHI}$. Tween $80(0.05 \%)$ was added to liquid broth to avoid clumping except for capsule analysis.

\subsection{Plasmids}

Plasmids pCGL482 [14], pVWEx2 [15], pMV261-Gm (derivative of pMV261) [16] and pVV16 [17] were used as expression vectors in C. glutamicum, M. smegmatis and $M$. tuberculosis respectively. When appropriate, antibiotics were added at the following concentrations: kanamycin $(\mathrm{Km}) 25 \mu \mathrm{g} . \mathrm{ml}^{-1}$, chloramphenicol $(\mathrm{Cm}) 6 \mu \mathrm{g} . \mathrm{ml}^{-1}$ for $C$. glutamicum or $30 \mu \mathrm{g} . \mathrm{ml}^{-1}$ for E. coli, gentamycin $(\mathrm{Gm}) 10 \mu \mathrm{g} . \mathrm{ml}^{-1}$, hygromycin (Hyg) $25 \mu \mathrm{g}$. $\mathrm{ml}^{-1}$ and tetracyclin $10 \mu \mathrm{g} \cdot \mathrm{ml}^{-1}$.

Cloning of Cg-pmt and Ms-pmt in C. glutamicum : The pmt genes of C. glutamicum Cgpmt (Cg1014 or NCgl0854) and M.smegmatis Ms-pmt (Msmeg_5447) [4] were cloned under the tac promoter into the expression vector pVWEx2 [15]. The pmt genes were amplified from the genomic DNA of C. glutamicum ATCC13032 or M. smegmatis mc $^{2} 155$ by PCR using the primers DirCgPmt-Xbal and RevCgPmt6His-Bg/2 or DirMsmPmt-Xbal and RevMsmPmt6HisBamHI respectively (Table 1). The PCR products were digested with Xbal and Bg/2 or Xbal and 
$\mathrm{BamHI}$ and cloned into the $\mathrm{Xbal}$ - and BamHI-digested pVWEx2 resulting in the pmt-expressing plasmids pVWEx2-CgPmt-His and pVWEx2-MsPmt-His.

Cloning IppX-tb in M. tuberculosis: Cloning of IppX-tb and IppX-tb $\Delta \mathrm{S} 16 \mathrm{~T} 18 \mathrm{~A}$ in the mycobacterial expression vector pVV16 was performed by PCR as described in Sulzenbacher et al. [7] except for the DNA template. Here we used plasmid pMV261 LppX-tb and pMV261 LppX-tb $\Delta$ S16 T18A as templates.

Transformation of the bacterial strains was performed by electrotransformation as described for E. coli [18], C. glutamicum [19], M. smegmatis and M. tuberculosis [20].

\subsection{Pmt gene disruption}

The pmt gene (Cg1014 or NCgI0854) of C. glutamicum ATCC13032 was interrupted by integration of non-replicative plasmid with a kanamycin resistance cassette into the $5^{\prime}$ part of the gene. Briefly, a $532 \mathrm{bp}$-DNA fragment of the $p m t$ gene was amplified by PCR using primers PMT1-3 and PMT1-4 (Table 1). The DNA fragment was cloned into the pPrime cloning vector (5PRIME) and used to transform $E$. coli as described by the manufacturer. The recombinant plasmid was transferred into $C$. glutamicum by electroporation and transformants were selected on $\mathrm{Km}$-containing plates. As the plasmid is unable to replicate into $C$. glutamicum, only the bacteria with the plasmid integrated into the genome were able to grow in presence of kanamycin. Correct integration of the plasmid into the pmt gene was checked by PCR analysis on the genomic DNA using combinations of primers localized upstream and downstream of the cloned 532 bp-DNA fragment (PMT1-1 and PMT1-6) and into the vector

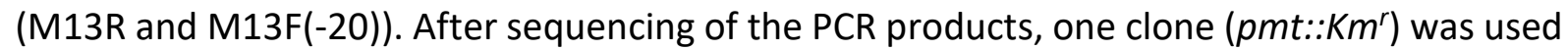
for further experiment. 


\subsection{Site directed mutagenesis of $L p p X-t b$}

Site-directed mutagenesis of the IppX-tb gene was performed by PCR-driven overlap extension [21]. The mutagenic primers and flanking primers used to generate the mutatedIppX-tb genes are listed below (Table 1). Plasmid pCGL482 [11] and pMV261 [8] both carrying the native LppX-tb gene with a hemagglutinin (HA) and a His 6 epitope fused to the 3 ' part of the gene were used as templates for PCR. The generated PCR fragments were digested with EcoRV-Xhol or EcoRI and cloned either into the EcoRV-Xhol digested pCGL482-AmyE [11] for C. glutamicum or the expression vector pMV261 for M. smegmatis. All the mutated genes were sequenced to confirm the mutations. All mutated IppX-tb genes contained the hemagglutinin and a His 6 epitope fused to their $3^{\prime}$ part.

\subsection{Purification of native LppX-tb and derivatives}

Purification of LppX-tb and mutated LppX-tb from C. glutamicum was performed as described in Mohiman et al. [11].

For purification from M. smegmatis, bacteria from liquid cultures were harvested and resuspended in a $50 \mathrm{mM}$ phosphate buffer $\mathrm{pH} 8.0$ containing 4-(2Aminoethyl)benzenesulfonyl fluoride hydrochloride (AEBSF, Sigma) as a protease inhibitor. Cells were broken using a one shot cell disrupter (CellD) at 30kPsi. Unbroken cells were removed by low speed centrifugation ( $4000 \mathrm{~g}$ for $15 \mathrm{~min}$ ) and the cleared supernatant was centrifuged at 106,000 $\mathrm{g}$ for $60 \mathrm{~min}$ (rotor Ti 50 Beckman). Total membranes were homogenized in a $50 \mathrm{mM}$ phosphate buffer $\mathrm{pH} 8.0$ containing 4\% LDAO (lauryl dimethylamine oxide) and stirred $1 \mathrm{~h}$ in order to efficiently solubilize membrane proteins. Insoluble material was removed by centrifugation at $106,000 \mathrm{~g}$ for $60 \mathrm{~min}$. The soluble membrane proteins were diluted twice and $\mathrm{NaCl}$ and imidazole were added to final concentrations of $50 \mathrm{mM}$ and 10 
$\mathrm{mM}$ respectively in $25 \mathrm{mM}$ phosphate buffer, 2\% LDAO, $\mathrm{pH}$ 8.0. Ni-NTA agarose previously equilibrated with $25 \mathrm{mM}$ phosphate buffer $\mathrm{pH} 8.0$ with $2 \%$ LDAO, $50 \mathrm{mM} \mathrm{NaCl}$ and $10 \mathrm{mM}$ imidazole was added to the soluble membrane proteins. The mixture was gently agitated for $1 \mathrm{~h}$ at $4^{\circ} \mathrm{C}$ and loaded in an empty column. The agarose resin was washed with ten volumes of $25 \mathrm{mM}$ phosphate buffer $\mathrm{pH} 8.0$ with $1 \% \mathrm{LDAO}, 50 \mathrm{mM} \mathrm{NaCl}$ and $20 \mathrm{mM}$ imidazole to remove weakly associated proteins. LppX-tb was eluted with the same buffer containing $50 \mathrm{mM}$ imidazole. The eluted samples were precipitated with trichloroacetic acid (TCA) $10 \%$ to concentrate the proteins. If necessary further purification of LppX-tb was performed with anti HA agarose (Pierce) instead of TCA precipitation.

\subsection{Extraction and analysis of proteins from different cellular localisation in C. glutamicum} and M. smegmatis

The proteins from the envelope and culture supernatant of C. glutamicum were prepared as follows. After growth, cells were separated from the culture supernatant by centrifugation at $7000 \mathrm{~g}$ for $10 \mathrm{~min}$. Proteins from the culture supernatant (S) were precipitated with $10 \% \mathrm{TCA}$ (Sigma) at $4^{\circ} \mathrm{C}$ for $30 \mathrm{~min}$. The pellet, recovered by centrifugation (13 $000 \mathrm{~g}, 10 \mathrm{~min}$ ), was washed with cold acetone and resuspended in TE buffer $\mathrm{pH} 8$ (Tris- $\mathrm{HCl}$ 10 mM EDTA 1 mM). Extraction of envelope proteins (E) of $C$. glutamicum was performed with SDS at high temperature. Briefly, the centrifuged cells were resuspended in Laemmli buffer and after heating $5 \mathrm{~min}$ at $100^{\circ} \mathrm{C}$, cells were discarded after centrifugation. The supernatant containing the envelope proteins $(\mathrm{E})$ and the proteins from the culture supernatant $(\mathrm{S})$ were analyzed on SDS PAGE. 
191

192

193

194

195

performed as described by Sani et al. [22] using $1 \%$ Tween 80 and the proteins were precipitated with TCA before analysis on SDS PAGE.

\subsection{Western blotting}

Protein extracts ( 5 to $10 \mu \mathrm{g}$ of total protein) were separated by SDS-PAGE (12\%) and transferred to nitrocellulose membrane. Immunoblotting was performed using either antiHis6, anti-HA- or Concanavalin A peroxidase-conjugates (Roche) as recommended by the manufacturer. The blots were developed using clarity western ECL substrate (Bio-Rad). The ImageQuant LAS 500 was used for chemioluminescence detection.

\subsection{Mass spectrometry analysis}

\section{-Sample preparation-.}

LppX SDS-PAGE bands, corresponding to different strains, were excised from the gel after Coomassie Blue staining. In-gel enzymatic digestion was performed using standard conditions. Briefly, protein bands were extensively washed with acetonitrile (ACN) and 100 $\mathrm{mM}$ ammonium carbonate. The excised bands were treated with $10 \mathrm{mM}$ dithiothreitol (DTT) at $56{ }^{\circ} \mathrm{C}$ for $30 \mathrm{~min}$. After DTT removal, cysteine carbamidomethylation was performed at room temperature for $30 \mathrm{~min}$ by addition of $55 \mathrm{mM}$ iodoacetamide. After removal of the supernatant, the washing procedure was repeated, and gel slices were dried. Tryptic digestion was performed overnight at room temperature by addition of $20 \mu \mathrm{l}$ of $10 \mathrm{ng} / \mu \mathrm{l}$ Porcine Gold Trypsin (Promega) diluted in $50 \mathrm{mM}$ ammonium carbonate. Proteolytic peptides were extracted first by addition of $20 \mu \mathrm{l}$ of $50 \% \mathrm{ACN}$ and $0.1 \%$ formic acid and second by addition of $20 \mu \mathrm{l}$ of $100 \%$ ACN. Tryptic peptides extracted were vacuum dried and resuspended in 
$0.05 \% \mathrm{ACN}$ and $0.1 \%$ trifluoroacetic acid (TFA) prior to nano LC-MS/MS mass spectrometry

213

214

215

216

217 analysis.

\section{-Nano LC-MS/MS analysis-}

Nano LC-MS/MS analysis were performed with the triple-TOF 4600 mass spectrometer (Absciex, Framingham, MA, USA) coupled to the Nano-RSLC system (Thermoscientific). Briefly, peptides were desalted on a C18 reverse phase pre-column (C18 Acclaim Pepmap100, 3 um, $100 \AA$, $75 \mu \mathrm{m}$ i.d., $2 \mathrm{~cm}$ length) using a loading buffer containing $\mathrm{H}_{2} \mathrm{O} / \mathrm{ACN} / \mathrm{TFA}$ $(98 \% / 2 \% / 0.05 \%)$ at $5 \mu \mathrm{l} / \mathrm{min}$ and were then eluted at a flow rate of $300 \mathrm{nl} / \mathrm{min}$ from the reverse phase analytical C18 column (C18 Acclaim Pepmap100, $2 \mu \mathrm{m}, 100 \AA$, $75 \mu \mathrm{m}$ i.d., $50 \mathrm{~cm}$ length) using a $5-35 \%$ solvent B gradient for 40 min. Solvent B was $0.1 \%$ formic acid in $100 \%$ ACN and solvent $A$ was $0.1 \%$ formic acid in water. Nano LC-MS/MS experiments were conducted in Data Dependent acquisition method by selecting the 20 most intenses precursors for CID fragmentation with Q1 quadrupole set at low resolution for better sensitivity and with a collision energy ramp ( $\pm 15 \%)$ set to $35 \mathrm{~V}$.

\section{-Data analysis-}

Raw data were processed using MS data converter software (Absciex) and protein identification was performed using the MASCOT search engine (Matrix science, London, UK) against LppX sequences with carbamidomethylation of cysteines set as fixed modification. Oxydation of methionines and glycosylation of serine and threonine were set as variable modifications. Peptide and fragment tolerance were respectively set at $25 \mathrm{ppm}$ and $0.05 \mathrm{Da}$. Only peptides with mascot ions score higher than the identity threshold (30) at less than $1 \%$ of false positive discovery rate are considered. For relative quantification of the $\operatorname{LppX} \mathrm{P}_{6-29}$ 
234 glycoforms, MS extracted ion chromatogram (XIC) were realized on $\mathrm{LppX}_{\mathrm{P}-29}$ harboring 235 glycosylation using peakview software 1.2 (Absciex).

236 2.9. Lipids extraction from culture supernatants, cell surface and cells of $M$. tuberculosis Culture supernatants $(50 \mathrm{ml})$ were sterilized by filtration, lyophilized and lipids were extracted following Bligh and Dyer protocol [23] and analyzed by LC/MS. Cells obtained from $239100 \mathrm{ml}$ cultures were extracted with $3 \mathrm{ml}$ of water-saturated butanol for $16 \mathrm{~h}$. The butanol extracts were collected and filter sterilized. The remaining cell pellets were extracted with 241 chloroform: methanol (1:2, v:v) once and chloroform: methanol (2:1, v:v) twice. The combined 242 extracts were subjected to Folch wash, dried and analyzed by LC/MS. LC/MS was performed using an electrospray ionization/atmospheric pressure chemical ionization source in the

244 positive mode on an Agilent 6220 time-of-flight mass spectrometer equipped with a 245 MultiMode Source. 


\section{Results}

\subsection{Identification of the glycosylation sites of LppX-tb in C. glutamicum}

In a previous study, we reported that LppX-tb was O-glycosylated in C. glutamicum

[11]. The glycosylation sites were located within the N-terminal part of LppX-tb between

251

252

amino acids 6 and 29 (Fig. 1). MS analysis identified heterogeneously glycosylated forms of LppX-tb carrying from 1 to 4 hexose units. In this study, we tried to identify the glycosylation site(s) within the peptide using conventional CID MS/MS techniques but unfortunately this was not successful. To determine the residues targeted by glycosylation in LppX-tb we thus performed a PCR-mediated approach to generate site-directed mutagenesis of putative glycosylation sites within the N-terminal part of LppX-tb. In this part of the polypeptidic chain, 3 hydroxyl-bearing amino acids were present (serine S16 and S20, threonine T18). All were predicted as putative glycosylation sites (Fig. 1) by the NetOGlyc 4.0 software [24]. Threonine T18 and serine S20 were individually substituted by an alanine leading to the mutated-genes LppX-tb T18A and LppX-tb S20A. As we failed in replacing serine S16 by alanine, this serine was deleted leading to the mutated-gene $L p p X-t b \Delta S 16$. All mutated-genes were generated by PCR and cloned into the $C$. glutamicum expression vector pCGL482 under the control of the amyE promoter [11]. Recombinant strains were grown in $\mathrm{BHI}$ at $30^{\circ} \mathrm{C}$ overnight. After growth, cells were separated from the media by centrifugation and broken. Unbroken cells were removed and total membranes (inner and outer membranes) were recovered by high speed centrifugation. The membranes were solubilized in LDAO and solubilized membrane protein extracts were loaded on Ni-NTA column to purify the native and mutated His tagged LppX-tb. The purified proteins were analyzed by MS. 

native LppX-tb protein (Fig. 2A): the peptide with no modification $\left(P_{6-29}\right)$, the peptide with 1, 2, 3 and 4 hexose units $\left(\mathrm{P}_{6-29} \mathrm{Hex} 1, \mathrm{P}_{6-29} \mathrm{Hex} 2, \mathrm{P}_{6-29} \mathrm{Hex} 3\right.$ and $\left.\mathrm{P}_{6-29} \mathrm{Hex} 4\right)$. The $\mathrm{P}_{6-29} \mathrm{Hex} 2$ form was the most abundant form detected (Fig. 2B). Analysis of the mutants shows no difference in the glycosylated pattern between the native LppX-tb and LppX-tb S20A. For the mutants LppX-tb $\Delta \mathrm{S} 16$ and T18A, only $\mathrm{P}_{6-29}$ and $\mathrm{P}_{6-29}$ Hex2 were detected. A double-mutated LppX-tb gene $\Delta \mathrm{S} 16-\mathrm{T} 18 \mathrm{~A}$ was finally constructed and did not reveal any glycosylated peptide (Fig. 2C). All these results demonstrate that S16 and T18 are both native glycosylation sites and that each site is diglycosylated in the native protein. It is interesting to note that the glycosylation of S16 and T18 was not depending on each other. Moreover, despite modification of the glycosylation pattern, LppX-tb variants $\Delta \mathrm{S} 16, \mathrm{~T} 18 \mathrm{~A}$ and $\Delta \mathrm{S} 16-\mathrm{T} 18 \mathrm{~A}$ were still membraneassociated.

\subsection{Cg_PMT is essential for glycosylation of $L p p X-t b$ in C. glutamicum}

As seen previously, LppX-tb is O-glycosylated with hexoses but the exact chemical nature of the modification was not determined. Nevertheless alpha mannosidase deglycosylation experiment suggests that LppX-tb is indeed mannosylated in C. glutamicum [11]. A similar result is suggested in M. tuberculosis since LppX-tb was detected among the ConA affinity capture glycoproteome [6].

In C. glutamicum, different proteins were identified as glycosyltransferases. Among these proteins, Pmt (encoding gene $\mathrm{NCgl0854)}$ was identified as a protein O-mannosyl transferase which transfers mannose residues from lipid carriers to proteins [25]. To investigate the possible role of Pmt in the glycosylation process of LppX-tb, a mutant of pmt was constructed in C. glutamicum. The pmt mutant $\left(p m t:: \mathrm{Km}^{r}\right)$ was generated by integration 
of a kanamycin resistance cassette into the $5^{\prime}$ part of the gene and the broad glycosylation

293

294

295

protein pattern of the pmt mutant was tested. The wild type and $p m t:: \mathrm{Km}^{r} \mathrm{C}$. glutamicum strains were grown in BHI. The cells and culture supernatant were separated by centrifugation. Treatment of whole cells with high concentrations of SDS is known to release cell wall components without affecting cell integrity in Corynebacterium. This method was used to extract proteins from the envelope. Proteins from the culture supernatant were recovered by TCA precipitation. Both proteins from the envelope and culture supernatant were transferred on SDS-PAGE and analyzed by immunoblotting with Concanavalin A peroxidase conjugate. As seen in Fig. 3A, several glycoproteins were detected both in the envelope and supernatant culture of the wild type strain. As expected no ConA reactive glycoproteins were detected in the $p m t:: K m^{r}$ strain. The pmt gene of $C$. glutamicum (Cg-pmt) was cloned in the expressing vector pVWEx2 under the control of the tac promoter and the recombinant plasmid was transferred in the pmt mutant for complementation studies. When the wild type $p m t$ gene is expressed in $p m t:: K m^{r}$, glycoproteins are again detected with a similar pattern to the wild type strain whether IPTG was added or not. As described in Mahne et al [25], our results confirm that Pmt is responsible for the glycosylation of secreted proteins in the culture supernatants. In addition, in this study we detected other pmt-dependent glycosylated proteins associated to the cell envelope of $C$. glutamicum.

As the $p m t:: K m^{r}$ mutant was confirmed, we specifically checked if glycosylation of LppX-tb was dependent of this gene by expressing LppX-tb in the mutant pmt. The LppX-tb gene was cloned in the expression vector pCGL482 and used to transform the wild type and

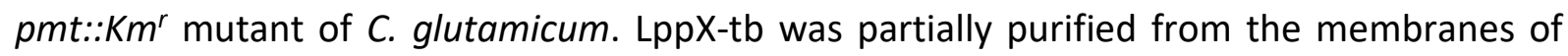
these strains and analyzed by SDS PAGE and western immunoblotting (Fig. 3B). As seen in Fig. $3 \mathrm{~B}$, a major protein of $25 \mathrm{kDa}$ was detected by Concanavalin $\mathrm{A}$ in the wild type strain. In the 
mutant $p m t:: \mathrm{Km}^{r}$, a major band was detected slightly below than in the wild type strain and was not detected by the Concanavalin A conjugate suggesting that LppX-tb is not glycosylated in the $p m t:: \mathrm{Km}^{r}$ mutant. To confirm that this is not related to a polar effect of the mutation, the pmt gene of $C$. glutamicum Cg-pmt cloned into the expression vector pVWEx2 was co

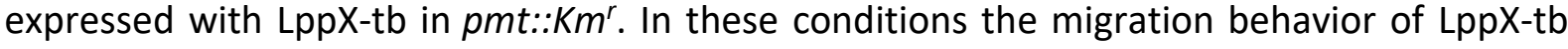
was restored. The corresponding band was detected by Concanavalin A whether IPTG was added or not. Glycosylation of LppX-tb in the complemented strain was definitively confirmed by MS analysis (Suppl. Fig. S1). As for the wild type, different glycoforms of the peptide were detected ( $\mathrm{P}_{6-29} \mathrm{Hex} 2$ and $\left.\mathrm{P}_{6-29} \mathrm{Hex} 4\right)$ as well as the 262 Da modification previously seen in LppXtb by Mohiman et al. [11]. In the mutant $p m t:: \mathrm{Km}^{r} \mathrm{MS}$ analysis confirmed that the peptide P629 was not glycosylated (Suppl. Fig. S1) which is in accordance with the absence of ConA binding seen on western immunoblot. These results demonstrate unambiguously that glycosylation of LppX-tb is dependent on Cg-pmt in C. glutamicum. (Msmeg_5447). The PMT proteins encoded by Ms-pmt from M. smegmatis or Cg-pmt from C. glutamicum are quite similar with a sequence identity of $42 \%$ (Suppl Fig. S2). Moreover some residues important for the catalytic activity [25] are conserved in both Ms-pmt and Cg-pmt. mutant with Ms-pmt was unsuccessful. Neither the glycoproteins from the envelope and supernatant culture nor LppX-tb were detected by Concanavalin A in the complemented strain (Fig 3C and 3D). The absence of glycosylation of LppX-tb was also confirmed by MS analysis. As the absence of glycosylation might be related to an expression problem, we tried to purify the protein PMT expressed from Ms-pmt during heterologous expression. The same experiment was performed with Cg-pmt as a positive control. In both cases, we were not able 
to detect the PMT proteins. Although this result suggests that very low amounts of Cg-PMT,

341 is sufficient to allow complementation, it does not allow us to conclude for the absence of

342 complementation by Ms-pmt.

\subsection{Glycosylation of LppX-tb in M. smegmatis}

Here, before proceeding on the role of LppX glycosylation, it was important to check whether LppX-tb glycosylation sites and pattern in Mycobacteria are the same as those found heterogously in C. glutamicum. For this, we choose to work in M. smegmatis, a fast growing species which is easily manipulated and in which several glycosylation studies have been performed so far.

M. smegmatis strain MC²155 carrying pMV261-LppX-tb [8] was grown in BHI and LppXtb was purified as described in materials and methods. A similar experiment was performed in parallel with C. glutamicum using pCg|482-LppX-tb. Both purified proteins were analyzed by western immunoblot using Concanavalin A peroxidase conjugate. As expected, LppX-tb was detected by the ConA conjugate when purified from C. glutamicum. Surprisingly, we were not able to visualize any signal when LppX-tb was purified from $M$. smegmatis suggesting that either LppX-tb is not mannosylated or that the glycosylation level of LppX-tb is not high enough to allow detection. In order to discriminate between these hypothesis, LppX-tb was analyzed by MS analysis. As shown in Fig. 4, LppX-tb purified from M. smegmatis was found to be glycosylated on the $\mathrm{N}$-terminal part of the protein. Several forms of peptide $\mathrm{P}_{6-29}$ were detected. The non-glycosylated form was the most abundant but small amounts of the Hex1 and Hex2 glycoforms were also detected. This low amount of glycoforms detected in $M$. smegmatis may account for the absence of detection by Concanavalin A. 

of the putative glycosylation sites S16, T18 and S20 of LppX-tb were generated according to the same procedure as for $C$. glutamicum except that the mutated genes were cloned in pMV261 an expression vector for mycobacteria. The recombinant plasmids were introduced into M. smegmatis $\mathrm{MC}^{2} 155$ and the strains were grown in Middlebrook $7 \mathrm{H} 9$ broth supplemented with Middlebrook ADC enrichment and 0.5\% glycerol and Tween 80 (0.05\%). The different LppX-tb proteins were purified from the membrane fraction as described in materials and methods and analyzed by MS (Fig. 5). When expressed in M. smegmatis, different glycoforms of the peptide (peptide with no modification $\mathrm{P}_{6-29}$, peptide with 1 and 2 hexose units respectively $\mathrm{P}_{6-29} \mathrm{Hex} 1$ and $\mathrm{P}_{6-29} \mathrm{Hex} 2$ ) were detected with native LppX-tb as well as with the variant $L p p X-t b S 20 A$. For the variant $L p p X-t b \Delta S 16$ and $T 18 \mathrm{~A}$, only $\mathrm{P}_{6-29}$ and $\mathrm{P}_{6-29}$ Hex1 were detected demonstrating that both S16 and T18 are glycosylation sites and that each site can be monoglycosylated. This was confirmed by analysis of the double mutant LppXtb $\triangle \mathrm{S} 16 \mathrm{~T} 18 \mathrm{~A}$ in which no glycosylated peptide could be found. As for $C$. glutamicum it is interesting to note that the glycosylation of S16 and T18 was not depending on each other.

These results show that the residues targeted by glycosylation in LppX-tb are identical in both C. glutamicum and M. smegmatis. This result is in line with a recent work supporting similar process of glycosylation in M. smegmatis and M. tuberculosis [26]. In our work, when expressed in M. smegmatis, LppX-tb was detected in the membrane fraction. In M. tuberculosis and M. bovis LppX-tb and its ortholog were found associated to the outermost layers of the cells that is the cell wall [27-29] and the cell surface [27]. In these 
mycobacteria, the cell wall is surrounded by a capsular layer [22]). We decided to analyze the mycobacterial capsular layer of $M$. smegmatis to see if $L p p X$ could also reach this outerlayer and whether S16 and T18 glycosylation was necessary for this localization.

The mycobacterial capsular layers of the different $M$. smegmatis strains $M^{2} C^{2} 155$ carrying pMV261, pMV261-LppX-tb and pMV261 LppX-tb $\Delta$ S16 T18A were extracted from the cells as described by Sani et al. [22]. For this experiment Tween 80 was not added in the culture media since this detergent is known to shed the capsule into the medium. After extraction, the proteins of the mycobacterial capsular layer were precipitated with TCA and analyzed by SDS PAGE and immunoblotting (Fig. 6A). The non-recombinant strain was used as a negative control. As seen in Fig. 6A similar amounts of proteins were extracted from the different strains. According to the immunoblot, LppX was only detected in the outerlayer of both recombinant strains whether S16 and T18 residues of LppX were modified or not.

As we noticed minor differences on SDS PAGE patterns of the different strains, an additional capsular extraction was performed and the protein content of the mycobacterial capsular layers were further analyzed on $8 \%$ SDS-PAGE (Fig. 6B). As seen in Fig. 6B, an additional protein was specifically detected in the strain expressing the $\Delta \mathrm{S} 16 \mathrm{~T} 18 \mathrm{~A}$ variant of LppX-tb. This protein was identified by MS as the 60-kDa chaperonin GroEL1 from M. smegmatis (Suppl Fig. S3). Interestingly, the presence of GroEL1 in the capsule layer of $M$. smegmatis and $M$. tuberculosis was previously reported [22]. Here we show that this protein is specifically enriched in the capsule of $M$. smegmatis expressing the LppX-tb $\triangle \mathrm{S} 16 \mathrm{~T} 18 \mathrm{~A}$ variant and this may suggest a specific function related to the absence of LppX glycosylation.

3.5. The $\triangle S 16 T 18 A$ variant of $L p p X$-tb is still able to promote translocation of phthiocerol dimycocerosates to the surface of M. tuberculosis 
bacteria [7]. Since LppX-tb is necessary for translocation of these molecules to the surface of

M. tuberculosis and, because mannosylation was shown to contribute to $M$. tuberculosis

virulence, we reasoned that glycosylation of $L p p X-t b$ might be important for $L p p X-t b$ function.

$\mathrm{T}_{18} \mathrm{~A} L p p X$-tb gene. As previously described, in contrast to $M$. tuberculosis wild type strain, the LppX-tb null mutant fails to release DIM into the culture medium but retains the ability to translocate these lipids across the plasma membrane [7]. We therefore decided to check the repartition of DIM in various mutants: the LppX-tb knock-out strain and the knock-out strains complemented with native or mutated $L p p X$-tb cloned in the expression plasmid pVV16 (Fig. allowing the release of some outermost components of the cells in the culture media. In these conditions DIM molecules were present in the cells of all strains and all strains produced similar amounts of DIM (Fig. 7A). The chromatography profile of the DIM molecules was however slightly different in the LppX-tb knock-out cells as compared to the other cells. As expected and seen previously [7] DIM molecules were absent from the culture filtrates of the knock-out strain. However DIM molecules were present in the culture filtrates of all complemented strains including the strain harboring the double mutation $\Delta \mathrm{S}_{16} \mathrm{~T}_{18} \mathrm{~A}$ (Fig. $7 \mathrm{~A}$ ). This result demonstrates that the presence of DIM in the culture filtrate of $M$. tuberculosis is not dependent on S16 and T18 LppX glycosylation of LppX-tb and therefore neither the localization of DIM in the outerlayer of M. tuberculosis. 

and culture filtrates of the two complemented mutants mainly contain DIM B molecules (Fig.

433 7B). Again the S16 and T18 LppX glycosylation state of LppX-tb has no impact in the 434 composition of DIM molecules. 


\section{Discussion}

In this article we used heterologous hosts to determine the glycosylation sites of the M. tuberculosis protein LppX-tb. A non glycosylated LppX-tb variant was then constructed and used to study the impact of glycosylation on LppX-tb function in M. tuberculosis.

4.1. The glycosylation sites S16 and T18 are localized in the unfolded N-terminal part of LppXtb

No specific target sequon is known for $\mathrm{O}$-glycosylation in contrast with $\mathrm{N}$-glycosylation. However $\mathrm{O}$-glycosylation sites are most often localized within regions of low sequence complexity [1]. Here in agreement with these studies we showed that LppX-tb glycosylation sites are localized in the $\mathrm{N}$-terminal region of the lipoprotein LppX-tb in a region lacking any secondary structure [7]. Moreover as seen for other mannosylated mycobacterial proteins $[5,30]$ these modified sites are within a region enriched with amino acids proline and alanine. Both S16 and T18 residues are also present in the corresponding LppX-tb ortholog of $M$. bovis suggesting potential glycosylation at the same residues in this protein. In the $M$. leprae, M. marinum M. ulcerans and M. gordonae LppX-tb-orthologs these residues differ at position 16 and/or 18 but their $\mathrm{N}$ terminal regions are enriched with threonine and serine residues with some of them predicted as potential glycosylation target (Suppl. Fig. S5).

4.2. The glycosylation sites S16 and T18 of LppX-tb are identical in C. glutamicum and M. smegmatis but the glycosylated forms detected are different.

Whether LppX-tb is expressed in C. glutamicum or M. smegmatis, the lipoprotein is found to be modified by a hexose (probably mannose) at exactly the same glycosylation sites. However the glycosylation pattern differs between both bacteria. In M. smegmatis up to 2 
457

458

459

460

461

462

463

464

465

466

467

468

469

470

471

472

473

474

475

476

477

478

hexoses are added to LppX-tb. The same result was reported during expression of LppX-tb in other mycobacterium species M. bovis BCG [9] and M. abscessus [10]. In C. glutamicum up to 4 hexose residues were found associated to LppX-tb during expression together with an unknown modification of 262 Da occasionally detected in the N-terminal peptide of LppX-tb as seen previously [11]. This modification was never detected when LppX-tb was expressed in M. smegmatis.

These results point out homologous sequence recognition in mycobacteria and corynebacteria but also minor differences reflecting their specific metabolism. In mycobacteria the highly glycosylated form of LppX-tb (Hex 3 and Hex 4) and the $262 \mathrm{Da}$ modification detected in C. glutamicum may either be absent and/or the amounts synthetized not high enough to allow detection.

\subsection{Glycosylation of LppX-tb is performed by Pmt}

In C. glutamicum the gene pmt (Cg1014 or NCgl0854) encoding for a mannosyltransferase responsible for protein-mannosylation was previously identified [25]. When expressed in the interrupted pmt mutant of $C$. glutamicum, LppX-tb is no longer glycosylated. Glycosylation is recovered when complementation with the Cg-pmt gene is performed. Thus our results confirm that Cg-pmt is involved in the glycosylation process of LppX-tb in addition to the polyprenol phosphate mannose synthase (cg-ppm1) and the apolipoprotein $\mathrm{N}$-acyl transferase (cg-ppm2 or Int) in C. glutamicum [11]. Moreover as previously proposed [11] mannosylation of LppX-tb is confirmed. The exact role of Cg-pmt remains to be elucidated since $\mathrm{Cg}$-pmt could be responsible both for the initial attachment of the mannosyl residue to the target residues and the elongation of the oligosaccharide chain. 
Alternatively other(s) glycosyltransferase(s) might be needed for the elongation step. Previously identified glycosyltransferases in C. glutamicum [31] could be involved.

No complementation was noticed during heterologous expression of Ms-pmt of $M$. smegmatis in the interrupted pmt mutant of $C$. glutamicum. This result was surprising since we already observed successful complementation of $C$. glutamicum mutant with a $M$. smegmatis gene [12]. However different hypothesis might explain this result. First during the mannosylation process Pmt transfers mannose from polyprenol phosphate mannose (PPM) to a target protein during its translocation across the membrane. In M. tuberculosis this process requires interaction with the Sec complex [32]. Thus the interaction of Ms-pmt with the Sec translocon of $C$. glutamicum might not be functional. Second the polyprenols involved in mannose translocation in actinomycetales differ in chain length and saturation of the isoprene unit [5]. Only C55-polyprenolmannose was detected in C. glutamicum [33] whereas C35, C40 and C50-PPM were found in M. smegmatis [34]. The protein Ms-pmt may not be able to recognize the C55-PPM of $C$. glutamicum and/or transfer the mannose. Finally the Ms-pmt may also be not correctly expressed or localized in the cell.

According to our results (that is evidence of mannosylation of LppX-tb in different actinobacteria and the role of $\mathrm{Cg}$-Pmt) and considering that the proteins Pmt from $\mathrm{C}$. glutamicum, M. smegmatis et M. tuberculosis are homologous [4,25] Sm-Pmt and Mt-Pmt are certainly responsible for $L p p X$-tb mannosylation in the respective bacteria. Moreover as the glycosylated residues of $L p p X-t b$ are the same in $C$. glutamicum and $M$. smegmatis we can conclude that Cg-Pmt and Sm-Pmt are able to recognize identical glycosylation pattern in LppX-tb. Although very likely, more experimental results are needed to expand this conclusion to a larger group of proteins. 
In lipoproteins, an intrinsically disordered domain is generally found between the $\mathrm{N}$ terminal lipid anchor and the functional domain of the protein [35]. Various functions are associated with intrinsically disordered proteins or regions such as connecting ordered domains, regulation, molecular recognition and signaling and assisting in protein folding [3]. In lipoproteins this unfolded domain contains the lipoprotein sorting signal and is thought to properly position the lipoprotein [35]. Moreover Prates et al. [3] proposed that the elongation effect due to glycosylation of unfolded domains may be important to provide the optimum distance between the connected domains for protein function. As the LppX-tb glycosylated residues were positioned in this part of the lipoprotein, glycosylation could act as a signal for its export and/or function. These data prompted us to evaluate the possible impact of LppXtb glycosylation on its localization and function. Our results show that the outerlayer localization of WT and modified LppX-tb $\Delta$ S16T18A in M. smegmatis is identical. Moreover LppX-tb harboring mutated S16 and T18 residues is still able to promote DIM translocation across the cell envelope in $M$. tuberculosis suggesting that its function is not significantly impaired. A similar result was also described for LprG, a structurally homolog protein of LppXtb. Indeed, LprG, which is $O$-mannosylated with a unique hexose on a threonine residue [26] was also shown to be essential for correct surface localisation of complex lipids (mannosecapped lipoarabinomannan (LAM)) in M. tuberculosis [36]. Interestingly, Alonso et al. showed that the surface localization of LAM in a pmt mutant of $M$. tuberculosis is not impaired [26].

Thus it seems that the distribution of complex lipids such as LAM and DIM in the mycobacterial cell is not dependent on the glycosylation state of their protein carriers LprG and LppX-tb 
525 respectively. Consequently these results suggest that the absence of LppX and LprG 526 glycosylation does not account for the attenuation of virulence observed in the pmt mutant.

In absence of mannosylation the function of $L p p X$ is not affected which is quite surprising as generally glycosylation is thought to affect protein folding and stability. However one can imagine that in the absence of glycosylation other factors may substitute for assisting LppX stability to maintain a sufficient level of DIM translocation at the cell surface. In that respect it is interesting to notice that Wang et al [37] previously discovered that the presence of phthiocerol dimycocerosates in M. bovis BCG is dependent on GroEL1. Because we show that the amount of GroEL1 is largely increased in the capsular layer of M. smegmatis only when the non-glycosylated variant of LppX-tb is expressed, it is thus tempting to propose that GroEL1 may be involved in the DIM translocation through an important role on LppX folding and/or stability. Indeed in the absence of glycosylation, the $\mathrm{N}$-terminal non ordered chain of LppX may not be correctly extended and this effect could be reversed by GroEL1 overexpression. By extension, in M. tuberculosis, overexpression of GroEL1 could also counteract the absence of glycosylation of LppX-tb $\Delta \mathrm{S} 16-\mathrm{T} 18 \mathrm{~A}$ and explain that DIM are still

541 translocated at the cell surface. Further experiments are needed to validate this attracting hypothesis. 
543 Conflict of interest

$544 \quad$ None declared 


\section{Acknowledgments}

546 This work has benefited from the facilities and expertise of the I2BC proteomic platform (Proteomic-

547 Gif, SICaPS) supported by IBiSA, lle de France Region, Plan Cancer, CNRS and Paris-Sud University. 
549 [1] Schäffer C, Messner P. Emerging facets of prokaryotic glycosylation. FEMS Microbiol Rev 2017;41:49-91. https://doi.org/10.1093/femsre/fuw036.

551 [2] Corfield A. Eukaryotic protein glycosylation: a primer for histochemists and cell biologists. Histochem Cell Biol 2017;147:119-47. https://doi.org/10.1007/s00418-016-1526-4.

553

[3] Prates ET, Guan X, Li Y, Wang X, Chaffey PK, Skaf MS, et al. The impact of O -glycan chemistry on the stability of intrinsically disordered proteins. Chem Sci 2018;9:3710-5. https://doi.org/10.1039/C7SC05016J.

[4] Liu C-F, Tonini L, Malaga W, Beau M, Stella A, Bouyssié D, et al. Bacterial protein-Omannosylating enzyme is crucial for virulence of Mycobacterium tuberculosis. Proc Natl Acad Sci U S A 2013;110:6560-5. https://doi.org/10.1073/pnas.1219704110.

[5] Espitia C, Servín-González L, Mancilla R. New insights into protein O-mannosylation in actinomycetes. Mol Biosyst 2010;6:775. https://doi.org/10.1039/b916394h.

[6] González-Zamorano M, Hernández GM, Xolalpa W, Parada C, Vallecillo AJ, Bigi F, et al. Mycobacterium tuberculosis glycoproteomics based on ConA-lectin affinity capture of mannosylated proteins. J Proteome Res 2009;8:721-33. https://doi.org/10.1021/pr800756a.

[7] Sulzenbacher G, Canaan S, Bordat Y, Neyrolles O, Stadthagen G, Roig-Zamboni V, et al. LppX is a lipoprotein required for the translocation of phthiocerol dimycocerosates to the surface of $\mathrm{N}$-acyltransferase (Lnt) in mycobacteria. J Biol Chem 2009;284:27146-56. 
571 [9] Brülle JK, Tschumi A, Sander P. Lipoproteins of slow-growing Mycobacteria carry three fatty acids and are N-acylated by Apolipoprotein N-Acyltransferase BCG-2070c. BMC Microbiol 2013;13. https://doi.org/10.1186/1471-2180-13-223.

[10] Becker K, Haldimann K, Selchow P, Reinau LM, Molin MD, Sander P. Lipoprotein glycosylation by protein-O-mannosyltransferase (MAB_1122c) contributes to low cell envelope permeability and antibiotic resistance of Mycobacterium abscessus. Front Microbiol 2017;8:1-12. https://doi.org/10.3389/fmicb.2017.02123.

[11] Mohiman N, Argentini M, Batt SM, Cornu D, Masi M, Eggeling L, et al. The ppm Operon Is Essential for Acylation and Glycosylation of Lipoproteins in Corynebacterium glutamicum. PLoS One 2012;7. https://doi.org/10.1371/journal.pone.0046225.

[12] Dautin N, Argentini M, Mohiman N, Labarre C, Cornu D, Sago L, et al. Role of the unique, nonessential phosphatidylglycerol::prolipoprotein diacylglyceryl transferase (Lgt) in Corynebacterium glutamicum. Microbiology 2020;166:759-76. https://doi.org/10.1099/mic.0.000937.

[13] Dusch N, Pühler A, Kalinowski J. Expression of the Corynebacterium glutamicum panD gene encoding L- aspartate- $\alpha$-decarboxylase leads to pantothenate overproduction in Escherichia coli. Appl Environ Microbiol 1999;65:1530-9.

[14] Schäfer A, Tauch A, Jäger W, Kalinowski J, Thierbach G, Pühler A. Small mobilizable multipurpose cloning vectors derived from the Escherichia coli plasmids pK18 and pK19: selection of defined deletions in the chromosome of Corynebacterium glutamicum. Gene 1994;145:6973. https://doi.org/10.1016/0378-1119(94)90324-7.

[15] Eikmanns BJ, Kleinertz E, Liebl W, Sahm H. A family of Corynebacterium glutamicum/Escherichia coli shuttle vectors for cloning, controlled gene expression, and promoter probing. Gene 1991;102:93-8. https://doi.org/10.1016/0378-1119(91)90545-M. 
595 [16] Stover, C., de la Cruz, V., Fuerst T et al. New use of BCG for recombinant vaccines. Nature 1991;351:456-60.

597

598

599

600

601

602

603

604

605

606

607

608

609

610

611

612

613

614

615

616

617

[17] Korduláková J, Gilleron M, Mikuová K, Puzo G, Brennan PJ, Gicquel B, et al. Definition of the first mannosylation step in phosphatidylinositol mannoside synthesis: PimA is essential for growth of mycobacteria. J Biol Chem 2002;277:31335-44.

https://doi.org/10.1074/jbc.M204060200.

[18] Dower WJ, Miller JF RC. Nucleic Acids Research erythocytes Nucleic Acids Research. Nucleic Acids Res 1981;9:2589-98.

[19] Bonamy C, Guyonvarch A, Reyes O, David F, Leblon G. Interspecies electro-transformation in Corynebacteria. FEMS Microbiol Lett 1990;66:263-9. https://doi.org/10.1016/03781097(90)90294-Z.

[20] Goude R, Roberts DM, Parish T. Electroporation of Mycobacteria. Methods Mol. Biol., vol. 1285, 2015, p. 117-30. https://doi.org/10.1007/978-1-4939-2450-9_7.

[21] Heckman KL, Pease LR. Gene splicing and mutagenesis by PCR-driven overlap extension. Nat Protoc 2007;2:924-32. https://doi.org/10.1038/nprot.2007.132.

[22] Sani M, Houben ENG, Geurtsen J, Pierson J, De Punder K, Van Zon M, et al. Direct visualization by Cryo-EM of the mycobacterial capsular layer: A labile structure containing ESX-1-secreted proteins. PLoS Pathog 2010;6. https://doi.org/10.1371/journal.ppat.1000794.

[23] Bligh, E.G. and Dyer WJ. Canadian Journal of Biochemistry and Physiology. Can J Biochem Physiol 1959;37.

[24] Steentoft C, Vakhrushev SY, Joshi HJ, Kong Y, Vester-Christensen MB, Schjoldager KT-BG, et al. Precision mapping of the human O-GalNAc glycoproteome through SimpleCell technology. EMBO J 2013;32:1478-88. https://doi.org/10.1038/emboj.2013.79. 
[25] Mahne M, Tauch A, Pühler A, Kalinowski J. The Corynebacterium glutamicum gene pmt encoding a glycosyltransferase related to eukaryotic protein-O-mannosyltransferases is essential for glycosylation of the resuscitation promoting factor (Rpf2) and other secreted proteins. FEMS Microbiol Lett 2006;259:226-33. https://doi.org/10.1111/j.15746968.2006.00269.x.

[26] Alonso H, Parra J, Malaga W, Payros D, Liu CF, Berrone C, et al. Protein O-mannosylation deficiency increases LprG-associated lipoarabinomannan release by Mycobacterium tuberculosis and enhances the TLR2-associated inflammatory response. Sci Rep 2017;7:1-14. https://doi.org/10.1038/s41598-017-08489-7.

[27] Lefèvre P, Denis O, De Wit L, Tanghe a, Vandenbussche P, Content J, et al. Cloning of the gene encoding a 22-kilodalton cell surface antigen of Mycobacterium bovis BCG and analysis of its potential for DNA vaccination against tuberculosis. Infect Immun 2000;68:1040-7. https://doi.org/\#.

[28] Mawuenyega KG, Forst C V., Dobos KM, Belisle JT, Chen J, Bradbury EM, et al. Mycobacterium tuberculosis Functional Network Analysis by Global Subcellular Protein Profiling. Mol Biol Cell 2005;16:396-404. https://doi.org/10.1091/mbc.e04-04-0329.

[29] Hermann C, Karamchand L, Blackburn JM, Soares NC. Cell Envelope Proteomics of Mycobacteria. J Proteome Res 2020. https://doi.org/10.1021/acs.jproteome.0c00650.

[30] Smith GT, Sweredoski MJ, Hess S. O-linked glycosylation sites profiling in Mycobacterium tuberculosis culture filtrate proteins. J Proteomics 2014;97:296-306. https://doi.org/10.1016/j.jprot.2013.05.011.

[31] Mishra AK, Krumbach K, Rittmann D, Appelmelk B, Pathak V, Pathak AK, et al. Lipoarabinomannan biosynthesis in Corynebacterineae: the interplay of two $\alpha(1 \rightarrow 2)$ mannopyranosyltransferases MptC and MptD in mannan branching. Mol Microbiol 
643

644

645

646

647

648

649

650

651

652

653

654

655

656

657

658

659

660

661

662

663

664

[32] VanderVen BC, Harder JD, Crick DC, Belisle JT. Export-mediated assembly of mycobacterial glycoproteins parallels eukaryotic pathways. Science 2005;309:941-3.

https://doi.org/10.1126/science.1114347.

[33] Gibson KJC, Eggeling L, Maughan WN, Krumbach K, Gurcha SS, Nigou J, et al. Disruption of CgPpm1, a Polyprenyl Monophosphomannose Synthase, and the Generation of Lipoglycan-less Mutants in Corynebacterium glutamicum. J Biol Chem 2003;278:40842-50. https://doi.org/10.1074/jbc.M307988200.

[34] Gurcha SS, Baulard AR, Kremer L, Locht C, Moody DB, Muhlecker W, et al. Ppm1, a novel polyprenol monophosphomannose synthase from Mycobacterium tuberculosis. Biochem J 2002;365:441-50. https://doi.org/10.1042/BJ20020107.

[35] Zückert WR. Secretion of bacterial lipoproteins: through the cytoplasmic membrane, the periplasm and beyond. Biochim Biophys Acta 2014;1843:1509-16. https://doi.org/10.1016/j.bbamcr.2014.04.022.

[36] Gaur RL, Ren K, Blumenthal A, Bhamidi S, Gibbs S, Jackson M, et al. LprG-Mediated Surface Expression of Lipoarabinomannan Is Essential for Virulence of Mycobacterium tuberculosis. PLoS Pathog 2014;10. https://doi.org/10.1371/journal.ppat.1004376.

[37] Wang X-M, Lu C, Soetaert K, S'Heeren C, Peirs P, Lanéelle M-A, et al. Biochemical and immunological characterization of a cpn60.1 knockout mutant of Mycobacterium bovis BCG. Microbiology 2011;157:1205-19. https://doi.org/10.1099/mic.0.045120-0.

[38] Madeira F, Park YM, Lee J, Buso N, Gur T, Madhusoodanan N, et al. The EMBL-EBI search and sequence analysis tools APIs in 2019. Nucleic Acids Res 2019;47:W636-41. https://doi.org/10.1093/nar/gkz268. 
Fig. 1. Amino acid sequence of the mature lipoprotein LppX. Bold letters indicate the

668

669

670

671

672

673

674

675

676

677

678

679

680

681

682

683

684

685

686

687

688

glycosylated peptide $\mathrm{P}_{6-29}$ identified by Mohiman et al. [11]. The HA and His 6 epitopes are highlighted. The underlined amino acids were predicted as putative glycosylated site (prediction with NetOGlyc 4.0 Server http://www.cbs.dtu.dk [24]).

Fig. 2. (A) Extracted ion chromatograms and (B) relative abundances of the LppX $P_{6-29}$ glycoforms observed during expression of wild type WT and mutated IppX $\Delta \mathrm{S} 16,-\mathrm{T} 18 \mathrm{~A}$ and S20A genes in C. glutamicum (CG). (C) Extracted ion chromatogram of LppX $\mathrm{P}_{6-29}$ glycoforms observed during expression of the mutated IppX $\Delta \mathrm{S} 16 \mathrm{~T} 18 \mathrm{~A}$ genes in C. glutamicum. All strains were grown in BHI. The different glycoforms detected are the peptide with no modification ( $\left.P_{6-29}\right)$, the peptide with $1,2,3$ and 4 hexose units (respectively $P_{6-29} \mathrm{Hex} 1, \mathrm{P}_{6-29}$ Hex2, $\mathrm{P}_{6-29}$ Hex3 and $\left.\mathrm{P}_{6-29} \mathrm{Hex4}\right)$. The amino acid sequence of the wild type and mutated $6-29$ peptides are mentioned in the right upper part of the figures using a red letter for the substituted amino acid and an asterisk for the deleted one.

\section{Fig. 3. Pmt dependent protein glycosylation in C. glutamicum.}

Western blot analysis of glycoproteins detected in the envelope (E) or in the culture supernatant $(\mathrm{S})$ of the wild type 13032 strain, $p m t:: K m^{r}$ mutant and $p m t:: K m^{r}$ mutant complemented by Cg-pmt (A) or Ms-pmt (C). Glycoproteins were detected using Concanavalin A peroxidase conjugate. Partial purification of LppX from the wild type strain $13032, p m t:: K m^{r}$ mutant and $p m t:: \mathrm{Km}^{r}$ mutant complemented by Cg-pmt (B) or Ms-pmt (D). (Left) Protein pattern on 12\% SDS PAGE after Coomassie blue staining. (Right) Glycoprotein pattern after Western immunoblot using Concanavalin A peroxidase conjugate.

For complementation studies cells were grown in presence (+) or absence (-) of IPTG. 
Fig. 4. (A) Relative abundance of the $\mathrm{LppX} \mathrm{P}_{6-29}$ glycoforms observed during expression of the wild type IppX gene (WT) in C. glutamicum (CG) and M. smegmatis (MS) grown in BHI. (B) Extracted ion chromatogram of the LppX $\mathrm{P}_{6-29}$ glycoforms detected in M. smegmatis (MS). The different glycoforms detected are the peptide with no modification $\left(P_{6-29}\right)$, the peptide with 1 , 2, 3 and 4 hexose units ( $\mathrm{P}_{6-29} \mathrm{Hex1}, \mathrm{P}_{6-29} \mathrm{Hex} 2, \mathrm{P}_{6-29} \mathrm{Hex3}$ and $\left.\mathrm{P}_{6-29} \mathrm{Hex} 4\right)$

Fig. 5. Relative abundances of the $L p p X P_{6-29}$ glycoforms observed during expression of WT and mutated Ippx $\Delta \mathrm{S} 16,-\mathrm{T} 18 \mathrm{~A},-\mathrm{S} 20 \mathrm{~A}$ and $\Delta \mathrm{S} 16-\mathrm{T} 18 \mathrm{~A}$ genes in M. smegmatis (MS) grown in Middlebrook 7H9 broth supplemented with ADC, glycerol and Tween. The different glycoforms detected are the peptide with no modification $\left(P_{6-29}\right)$, the peptide with 1 and 2 hexose units $\left(\mathrm{P}_{6-29} \mathrm{Hex} 1\right.$ and $\left.\mathrm{P}_{6-29} \mathrm{Hex2}\right)$.

Fig. 6. LppX is found in the outermost layer of M. smegmatis. M. smegmatis $\mathrm{Mc}^{2} 155$ carrying pMV261, pMV261-LppX and pMV261-LppX $\Delta \mathrm{S}_{16} \mathrm{~T}_{18} \mathrm{~A}$ were grown in Middlebrook 7H9 broth supplemented with $0.5 \%$ glycerol. Mycobacterial capsule proteins were extracted with Tween as described by Sani et al. [22], separated on a 12\% SDS-PAGE (A) stained with coomassie blue (Left) and analyzed by western-immunoblot using anti HA peroxidase conjugate (Right). Additional and refined analysis was performed on a 8\% SDS-PAGE stained with coomassie blue (B). The additional protein identified by MS is indicated $(\star)$.

Fig. 7. LC-MS analysis of the distribution of DIM in the cells (cells) and culture filtrates (Culture filtrate). (A) Extracted ion chromatograms of DIM molecules from the IppX knockout strain (KO) and the knock-out strains complemented with wild-type (WT) or mutated $(\Delta \mathrm{S} 16-\mathrm{T} 18)$ IppX. DIM molecules are absent from the culture filtrate of the knock-out strain, but present in the culture filtrates of both complemented mutant strains. (B) Mass spectra of DIM molecules extracted from the cells of the knock-out mutant, and from the culture filtrates 
712 of the mutant complemented with WT or mutated IppX. Note that the cells of the knock-out

713 strain contain mainly DIM A molecules whereas cells (Suppl. Fig. S4) and culture filtrates of 714 the two complemented mutants mainly contain DIM B molecules. DIM A molecules are 715 derivatives of DIM B molecules in which a keto group is replaced with a methoxy group at the 716 terminus of the molecules. The ${ }^{12} \mathrm{C}$ isotope peaks characteristic of DIM A and DIM B molecules 717 are labeled with their observed $m / z\left[M+N H_{4}\right]^{+}$values and their respective number of carbon 718 atoms.

719

720

721

722 
Table 1. Primers used in this study for the cloning and disruption of $p m t$ and obtention of the mutated IppX genes. The mutagenic and flanking primers used to generate site directed mutations in the IppX gene are indicated. The mutated $I p p X$ genes were cloned into the

727 expression vector pCGL482 and pMV261.

\begin{tabular}{|c|c|}
\hline Gene or plasmid & Primers \\
\hline \multirow{3}{*}{ Cg-pmt cloning } & DirCgPmt-Xbal 5'- CGCTCTAGAGCATCTAGCTTCCCACAAATGC-3' \\
\hline & RevCgPmt6His-Bg/2 5'-CGCAGATCTTTAATGATGATGATGATGATGGCGCCA \\
\hline & GCTTGGGAACC-3' \\
\hline \multirow[t]{3}{*}{ Ms-pmt cloning } & 'DirMsmPmt-Xbal 5' - GCGTCTAGAGCCGAGTGTCACGACCGACAGC-3' \\
\hline & RevMsmPmt6His-BamHI 5'-CGCGGATCCTTAGTGATGGTGATGGTGATGGCG \\
\hline & CCAGCTCGGCAACC-3' \\
\hline \multirow[t]{6}{*}{ pmt disruption } & PMT1-1 5'-GCCAAAGTTCAAGTGG-3' \\
\hline & PMT1-3 5'-TTACAGGTTTGAGCAGTGC-3' \\
\hline & PMT1-4 5'-ATACACCTGTGGTGAAAC-3' \\
\hline & PMT1-6 5'-AAGAGCTGCAGGATGGAGTC-3' \\
\hline & M13R 5'- CAGGAAACAGCTATGAC-3' \\
\hline & M13F(-20) 5'- GTAAAACGACGGCCAG-3' \\
\hline $\begin{array}{l}\text { Mutated IppX } \\
\text { gene : }\end{array}$ & Mutagenic primers \\
\hline \multirow[t]{2}{*}{$\operatorname{lpp} X \Delta \mathrm{S}_{16}$} & Rev LppX S16delta 5'-GGGTCGGACGCCGTCGGCACGGGAACACCCTGTTCC-3' \\
\hline & Dir LppX S16delta 5'-GGAACAGGGTGTTCCCGTGCCGACGGCGTCCGACCC-3’ \\
\hline \multirow[t]{2}{*}{$\operatorname{Ipp} X \mathrm{~T}_{18} \mathrm{~A}$} & Rev LppX T18A 5'-CGGGGTCGGACGCCGcCGGGCTCACGGG-3' \\
\hline & Dir LppX T18A 5'-CCCGTGAGCCCGGCGGCGTCCGACCCCG-3' \\
\hline \multirow[t]{2}{*}{$\operatorname{lpp} X \mathrm{~S}_{20} \mathrm{~A}$} & Rev Ippx-S20A 5'-CACTCGGGCTGCCGCCGGCTGGGGCGCGAGGAGC-3' \\
\hline & Dir LppX S20A 5’- GTGAGCCCGACGGCGGCCGACCCCGCGCTCCTCG-3’ \\
\hline \multirow[t]{2}{*}{ IppX $\Delta \mathrm{S}_{16}-\mathrm{T}_{18} \mathrm{~A}$} & RevS16deltaT18A 5'-CGGGGTCGGACGCCGcCGGCACGGGAACACC-3' \\
\hline & Dir S16 deltaT18A 5'-GGTGTTCCCGTGCCGgCGGCGTCCGACCCCG-3' \\
\hline Cloning plasmid & Flanking primers \\
\hline pMV261 & Dir pMV261 seq 5'- GGAATCACTTCGCAATGGCC- 3' \\
\hline
\end{tabular}


Rev LppX ECoRI 5'-CCACCACCATCACTAGAATTCGAGC-3'

pCGL482

482-S2 : 5' - GCAGAATAAATGATCCGTCG-3'

482-AS: 5'- GATATGATCATTTATTCTGC-3'

728

729 
CSSPKPDAEEQGVPVSIPIASDPALLAEIRQSLDATKGLTSVHVAVRTTGKVDSLGITS ADVDVRANPLAAKGVCTYNDEQGVPFRVQGDNISVKLFDDWSNLGSISELSTSIRVL DPAAGVTQLLSGVTNLQAQGTEVIDGISTTKITGTIPASSVKMLDPGAKSARPATVW IAQDGSHHLVRASIDLGSGSIQLTQSKWNEPVNVDYPYDVPDYATWHHHHНH 
Fig. 2

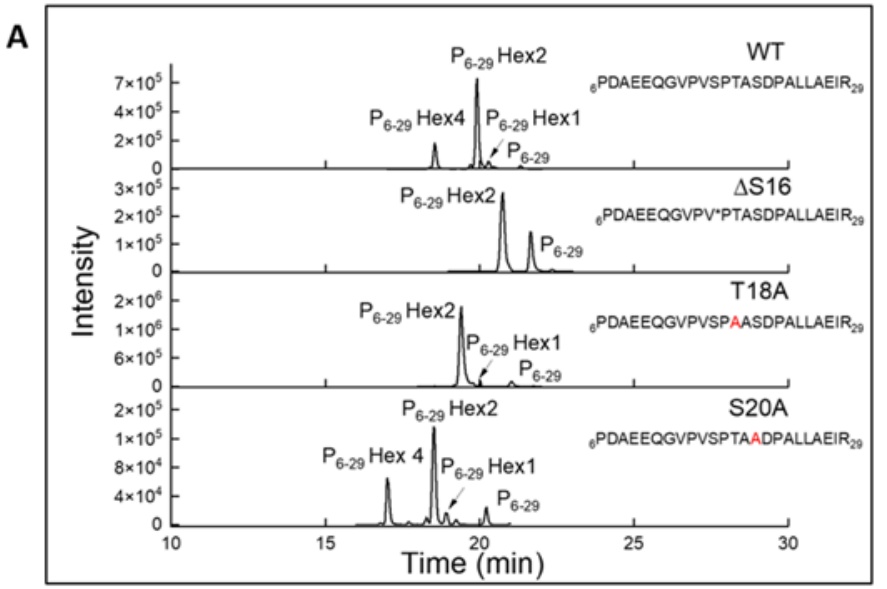

C

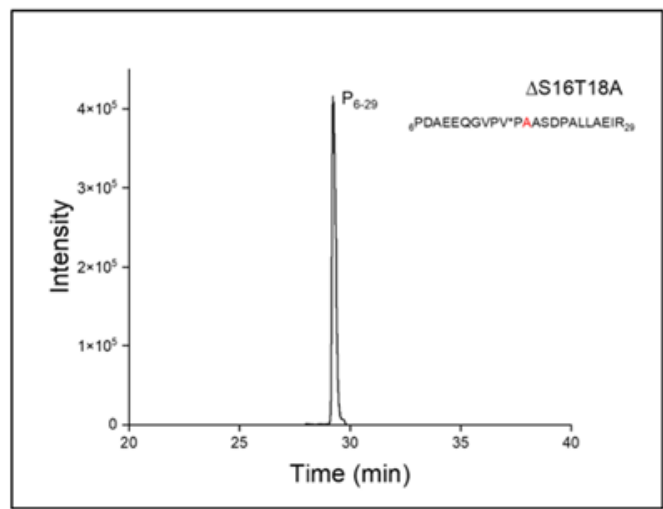

B

WT CG

Delta S16 CG

T18A CG

S2OACG

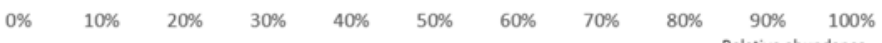

= $P_{6-29}=P_{6-29}$ Hex1 $\equiv P_{6-29}$ Hex2 $\quad P_{6-29}$ Hex4 Relative abundance 
Fig. 3
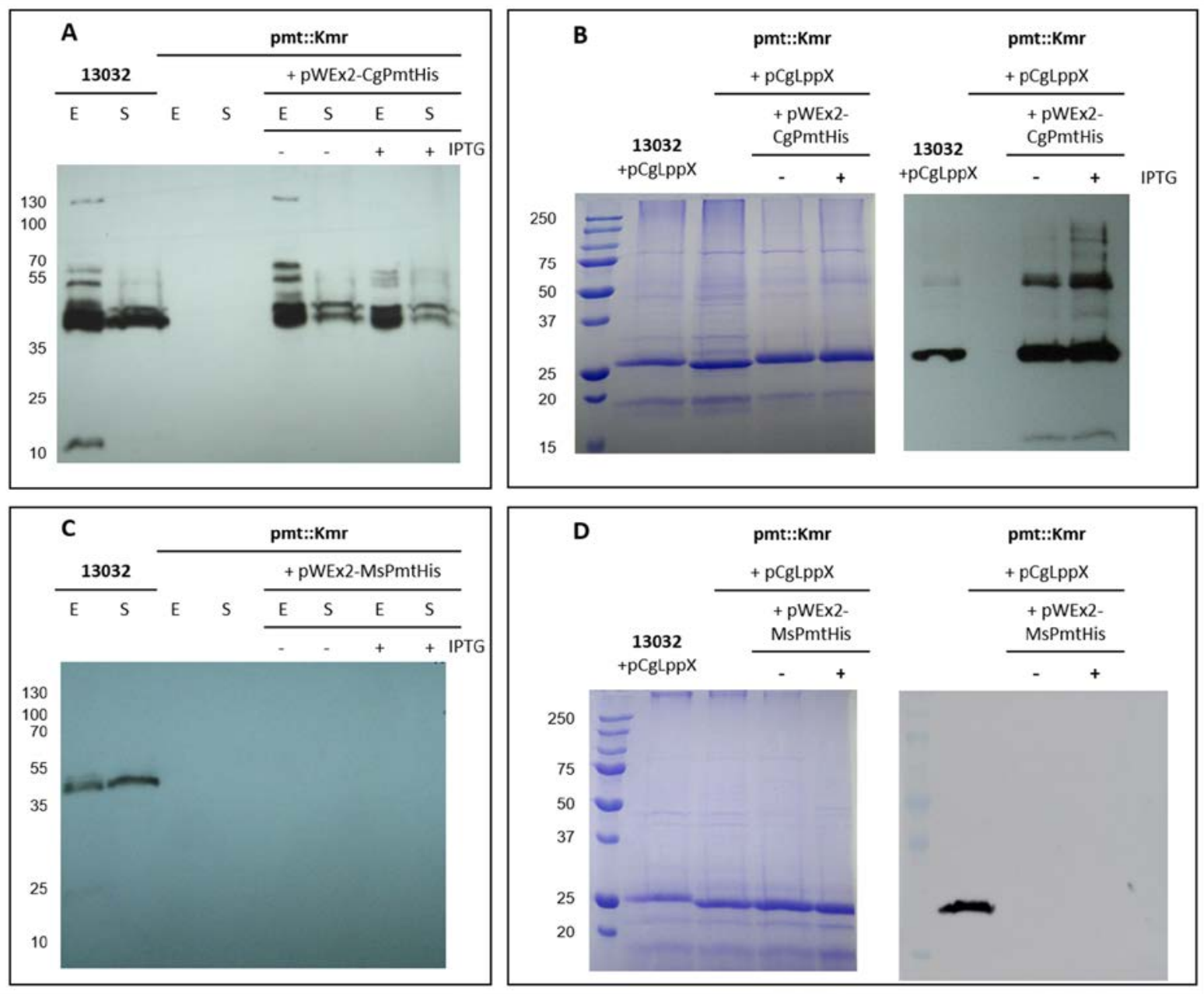

737 
Fig.4

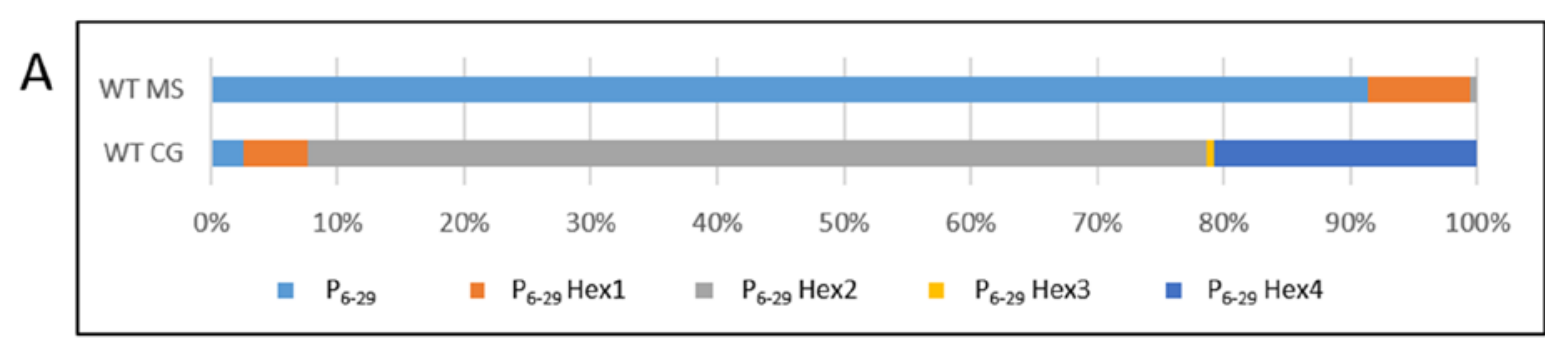

B

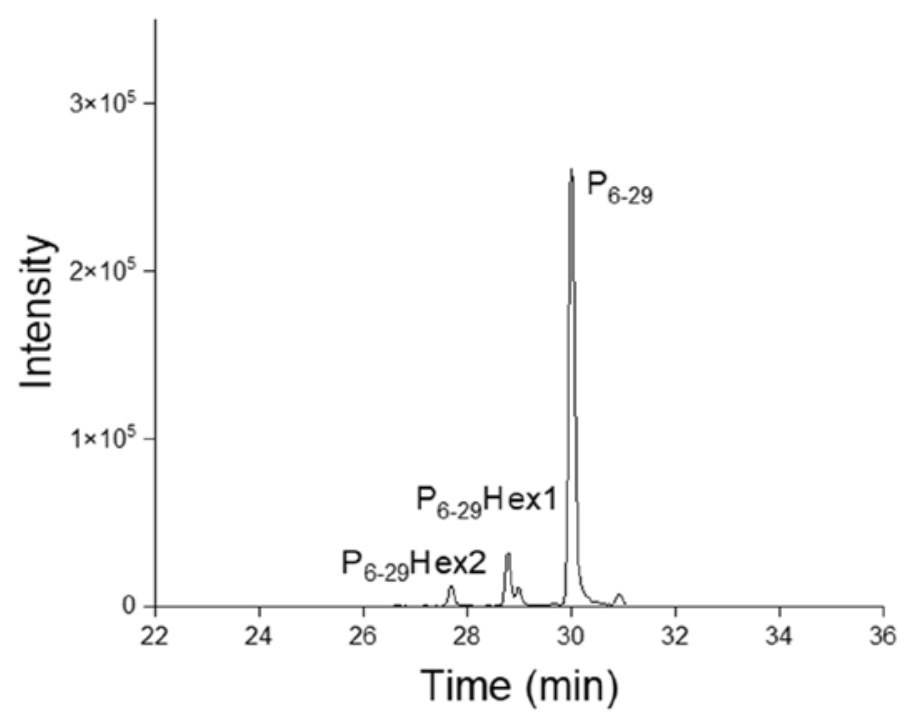

740 
$742 \quad$ Fig. 5

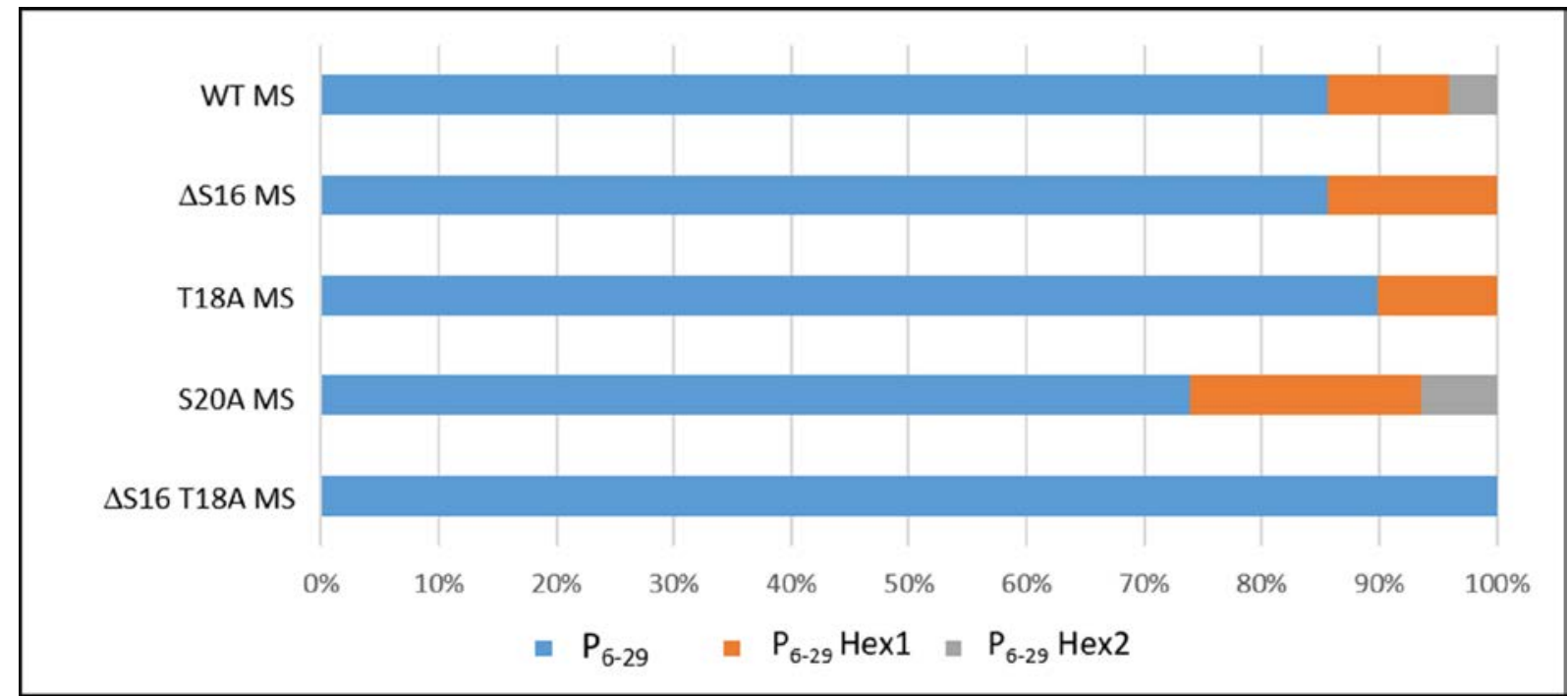

744 
Fig. 6
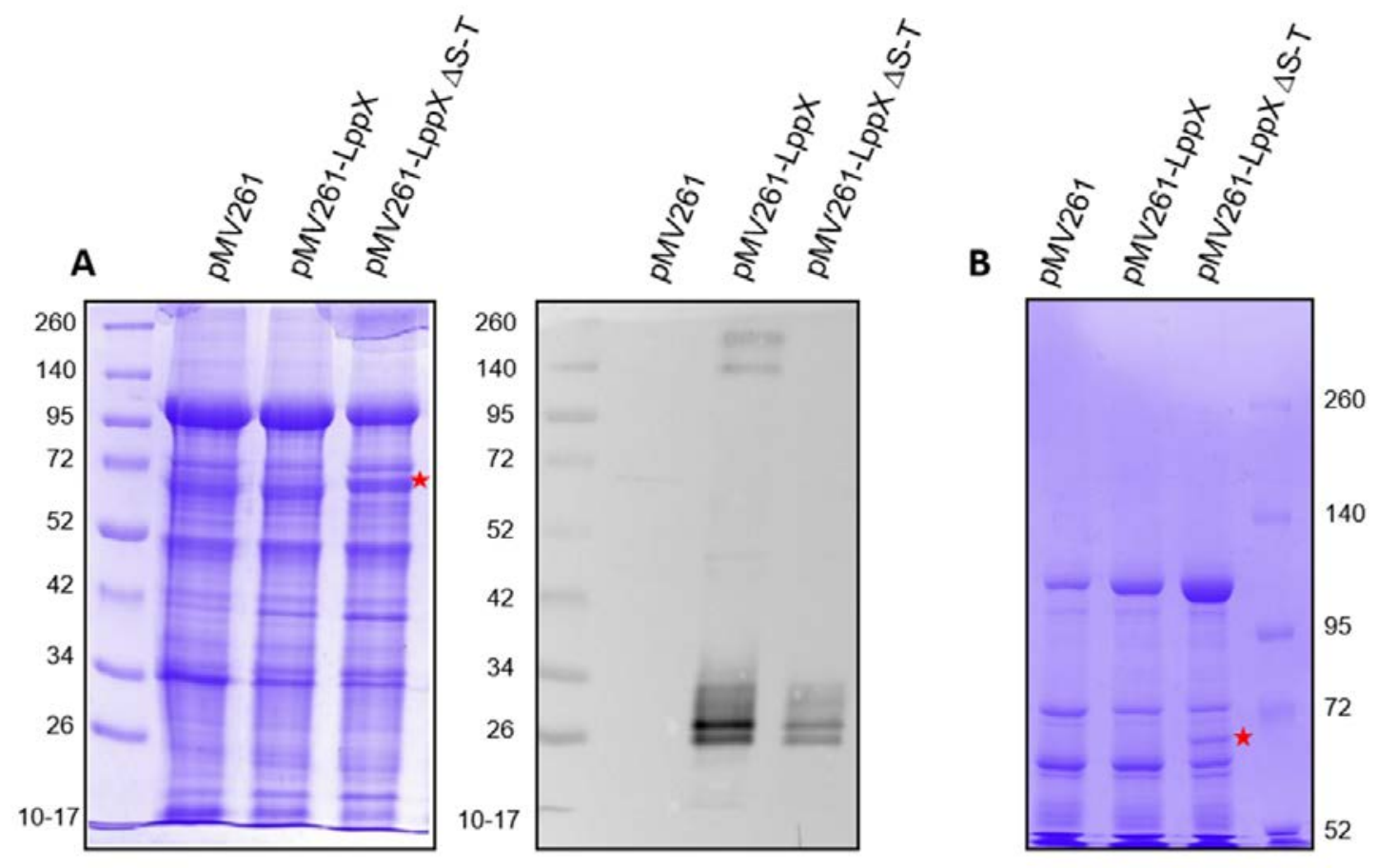

746

747 
Fig. 7

(A)

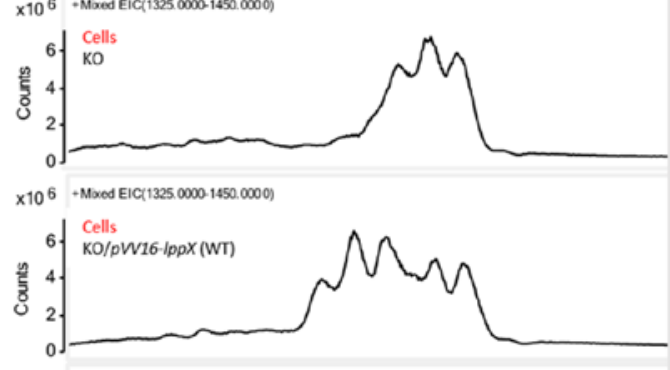

$\times 10^{6}$ - Mared EIC(1325 0000-1450.0000)

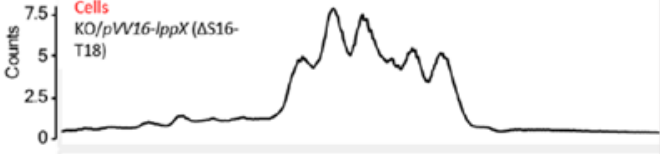

$\times 10^{6}$-Mrod EIC(1325. $0000-1450.0000$ )

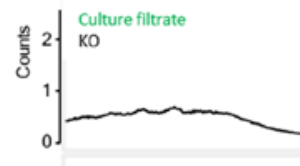

$\times 10^{6}$ - Mared EIC(1325.0000-1450.0000)

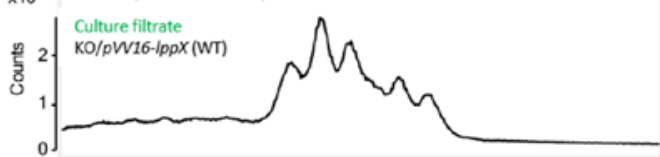

$\times 10^{6}$-Mred EIC(1325. 0000-1450.0000)

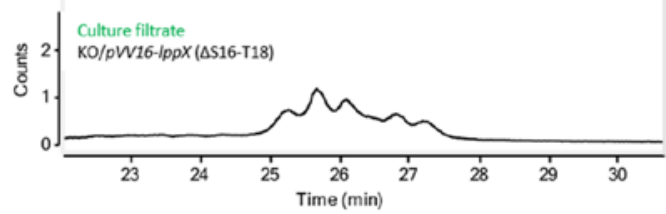

(B)
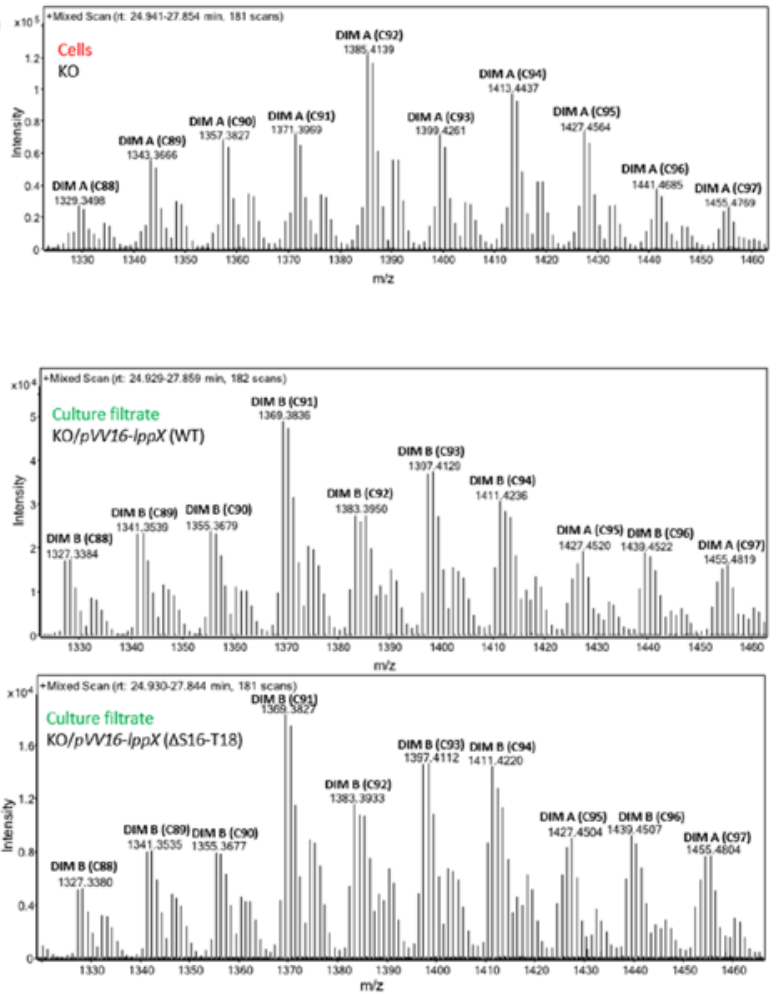


\section{Supplementary material}

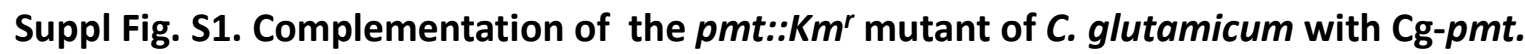

(A) Mass spectrum of the $\operatorname{LppX}_{6-29}$ peptide and (B) relative abundances of the $\operatorname{LppX} \mathrm{P}_{6-29}$ glycoforms observed during expression of IppX-tb in the pmt::Kmr mutant complemented by Cg-pmt of C. glutamicum. For the complementation studies cells were grown in presence (+) or absence (-) of IPTG. (C) Extracted ion chromatograms of the LppX $\mathrm{P}_{6-29}$ glycoforms observed during expression of IppX-tb in the C. glutamicum wild-type strain (WT) and $p m t:: K m^{r}$ mutant.

Suppl Fig. S2. Sequence alignement of the PMT protein from C. glutamicum (PMT_Coryneglu) and M. smegmatis (PMT_Mycosmeg) using EMBOSS Needle https://www.ebi.ac.uk [38] (Identity : 228/539 (42.3\%); Similarity : 310/539 (57.5\%); Gaps : 42/539 (7.8\%)). The conserved residues seen in various PMT proteins [25] are framed in blue.

Suppl Fig. S3. Mass spectrometry identification of the additional protein found in the outerlayer of $M$. smegmatis $M C^{2} 155$ expressing the modified LppX-tb $L p p X \Delta S_{16} T_{18} A$. Identified peptides (A) and sequence coverage (B) of the 60kDa Chaperonin 1 (OS=Mycobacterium smegmatis (strain ATCC $700084 / m c(2) 155)$ OX=246196 GN=groL1 PE=1 $S V=1$ ) resulting from in-gel trypsin digestion and Peptide-mass fingerprint (PMF) analysis.

Suppl. Fig. S4. Mass spectra of DIM molecules extracted from the cells of the IppX knock-out mutant (KO) complemented with WT or mutated ( $\triangle \mathrm{S} 16-\mathrm{T} 18)$ IppX. The ${ }^{12} \mathrm{C}$ isotope peaks characteristic of DIM A and DIM B molecules are labeled with their observed $m / z\left[\mathrm{M}+\mathrm{NH}_{4}\right]^{+}$ values and their respective number of carbon atoms.

Suppl. Fig. S5. N-terminal predicted amino acid sequences of the mature LppX-tb orthologs of Mycobacterium bovis, Mycobacterium leprae, Mycobacterium marinum, Mycobacterium ulcerans and Mycobacterium gordonae. The predicted $O$-glycosylation sites are indicated with 
774 bold letters (prediction with NetOGlyc 4.0 Server http://www.cbs.dtu.dk [24] and the position

775 of the glycosylated amino acids 16 and 18 in LppX-tb are framed in blue. 

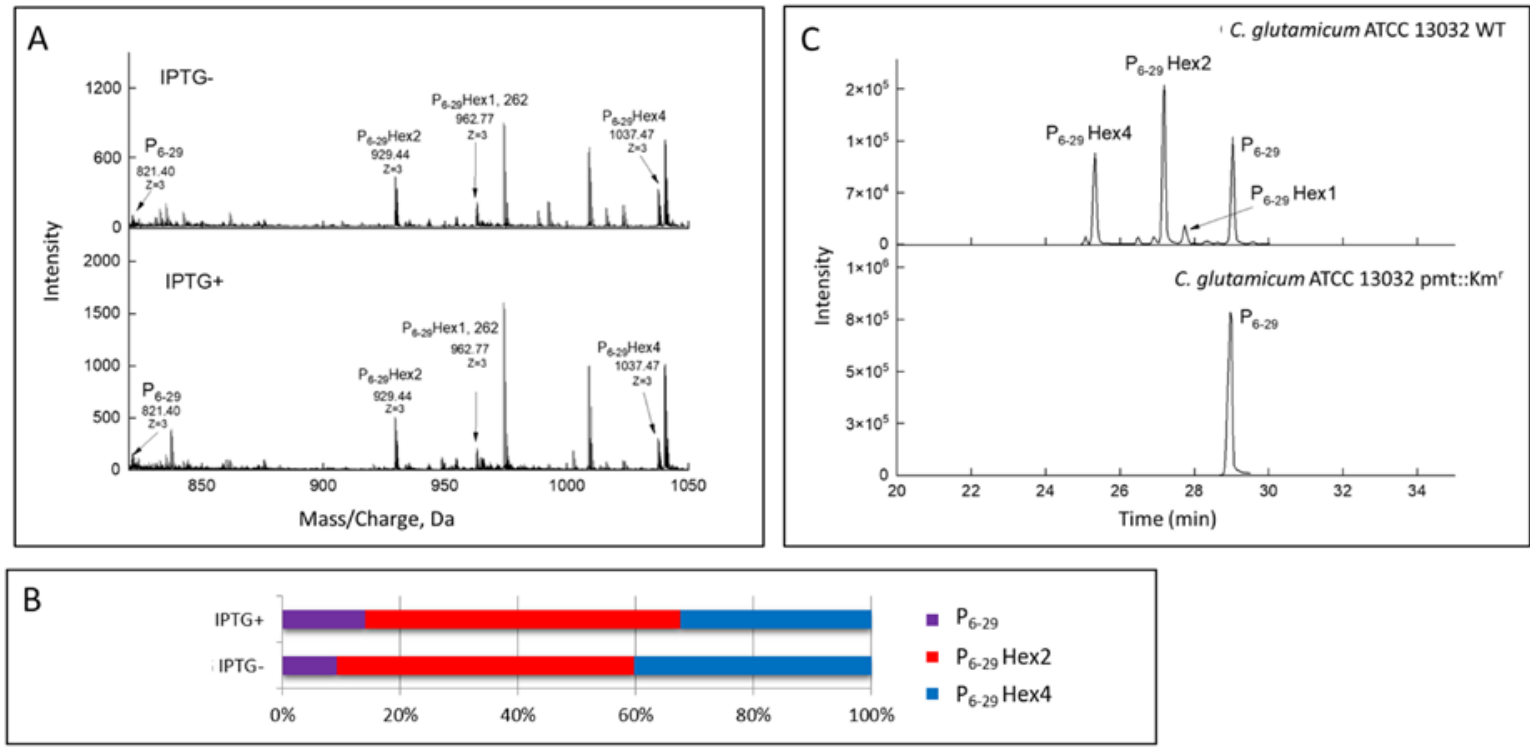

778 


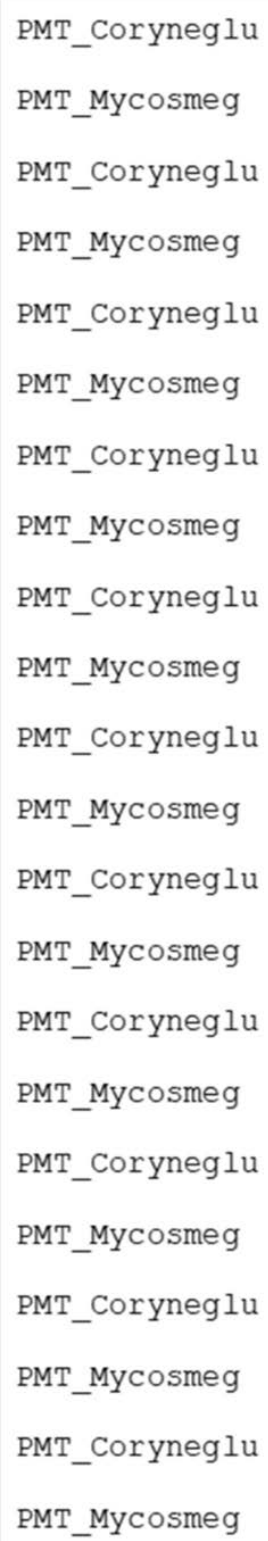

$$
1
$$$$
\text { MSQALPVRDQGRDQGIFAGTLPPAP PKFKWTRLD-TYTW- }
$$$$
\text { ..: : .।: }
$$$$
\text { |..... | | |.| }
$$$$
\text { . I I ... }
$$$$
1 \text { MTALDTDTPTAGRSAPL--------IS PGPVIP-PPDF--GPLDRAQGWA }
$$

39 --AIIAVFALVTRFTGLSSATASGTPVFDEKHYVPQAWDMVRSWINPITG ||$|\ldots| .:|||\ldots| .|.| .:|||:||||||||| \mid. .:: .:$

40 MTAIITALAA ITRFLNLGS PTDAGTPI FDEKHYAPQAWQVLHN------D

87 GIESNPGYGLVVHPPLAKQLEALGEWVFGYT PLGWRIMVAIFGTLTIFAI $|:| .|||||||||||:|||. .|:|||:|||\ldots||||\ldots|: . \mid .: . . .:$

84 GVEDNPGYGLVVHPPVGKQLIAIGEWLFGYNGLGWRFSGAVCGVIIVMLV

137 MAIARRLSGSTMVTF IAGI LALADGVLLVSSRFGMLDIFLVFF ITAAAWA $\ldots||||:||.|:| \ldots|||:| .:|||| \ldots|||| \ldots:||:|||.| \ldots|| \ldots$ 134 TRIARR ISRSTLVGA IAGLLI IADGVS FVSSRTALLDVFLVMFAVAAFAC

187 LIRDHQQMHQRLNDLLLTNGQITKD-FGPRFGFRWWRFTTGVFLGLALSV $|:.| \ldots|: .:|: \ldots .|:|:|.: .:| .|.| .|||||\ldots||||| \mid. .:$. 184 LMVDRDQVRERMYHAFL-DGRIAETRWGTRLGVRWWRFGAGVLLGLACAT

236 KWSGLYYIAFFGLTSVFLDLWLRKRYGVRRYVTGTLKNDVIPALGSLVII ||||||$:: .|||: .:: \ldots| \ldots||:|.| \ldots \ldots||:. .|:|.|\ldots \ldots:|$ 233 KWSGLY FVLF FGVMTLVFDAIARKQYHVPHPWRGMLRRDLGPAAYVFGLI

286 PALLYIWSWRAWFASETSVYRHAKTDGTITEDSILQLFPESIAGWIHYHI $|\ldots:|: .|: \ldots||||||:| .|:: \ldots:| \ldots|||| .:|::: \ldots| \mid \ldots$ 283 PFAVYLASYAPWFASETAVNRY-EVGRSIGPDSILPI-PDALRS LWHYTH

336 SVLEFHGSLTTSSGHSHPWDSKPWAWLVSGRPILYFSSTDISCDVGG--$: \ldots|| .:|| .: .|:|||:.|||| .|.:| .||:|| \ldots$. | |.|

331 AAYRFH SNLTNADGNHHPWESKPWTWPMSLRPVLYAIDNQ---DVPGCGA

383 -TCRRMIYLFGTPAIWWLTVPVI LWALWSFFARRSRGYVVPLVAFAAGFL $:|.: ..| .||||:|::|||:. .|||| \ldots|| \ldots|\ldots||.:||| \mid$. 378 QSCVKAVMLVGTPAMWFIAVPVLGWALWRTVVRRDWRYGAVLVGYMAGFL

432 PWLAAYDRQMYFFYATALVPFT I IMLALACGELWGRGKMTPTGLTRGSMA ||$.|\ldots||||||||||.:|.|.:: .:||\ldots|:: \ldots: \ldots .|\ldots| . \mid .:$. 428 PWFADIDRQMYFFYATVMA PFLVLAIALILGDILYKPNQNPERRTLGLLT

482 VVTYIS LVVMMFLAFSPLFYGFV IPDYVYESLMWFPSWR 520 $|\ldots|::||: \ldots|\ldots|: \ldots|\ldots| \ldots: \ldots:|||| \mid$. 
A.

Start - End Observed $\operatorname{Mr}(\operatorname{expt}) \quad \mathrm{Mr}(\mathrm{calc})$ $\begin{array}{lllll}4-12 & 1067.5026 & 1066.4953 & 1066.4931\end{array}$ $\begin{array}{llll}4-12 & 1067.5026 & 1066.4953 & 1066.4931 \\ 4-13 & 1223.6019 & 1222.5946 & 1222.5942\end{array}$ $\begin{array}{rrrr}4-13 & 1223.6019 & 1222.5946 & 1222.5942 \\ 18-27 & 987.5530 & 986.5458 & 986.5396\end{array}$ $\begin{array}{rrrr}18-27 & 987.5530 & 986.5458 & 986.5396 \\ 58-67 & 1264.5911 & 1263.5838 & 1263.5870\end{array}$ $\begin{array}{llll}58-67 & 1264.5911 & 1263.5838 & 1263.5870 \\ 79-100 & 2203.1602 & 2202.1529 & 2202.1492\end{array}$ $\begin{array}{lllll}105-117 & 1280.7460 & 1279.7387 & 1279.7360\end{array}$ $\begin{array}{lll}1477.7025 & 1476.6952 & 1476.6885\end{array}$ $\begin{array}{rrrr}276-283 & 875.4441 & 874.4368 & 874.4409\end{array}$ $\begin{array}{llll}349-362 & 1670.7175 & 1669.7102 & 1669.7067\end{array}$ $\begin{array}{lllll}379-390 & 1273.6810 & 1272.6737 & 1272.6673\end{array}$ $\begin{array}{rrr}1273.6810 & 1272.6737 & 1272.6673 \\ 995.5381 & 994.5308 & 994.5308\end{array}$ ppen M Peptide

2,110 K.TIAYDEEAR.R 0.371 K.TIAYDEEARR. 6.210 R.GLNSLADAVR. $Y$

-2.530 K.BIELEDPYRK. I

$1.681 \mathrm{~K} . \mathrm{KTDDVAGDGTTTATVLAQALVR.B}$

2.101 R. NVAAGANPLGLKR.G

4.550 K.GYISGYFVTDABR. $Q$

-4.731 K.APGPGDRR. $\mathrm{K}$

2.111 R.ABIENSDSDYDREK. L

5.011 K. AGAATEVELKRR. K

0.00701 K. HRIBDAVR.
$60 \mathrm{kDa}$ chaperonin 1 OS=Mycobacterium smegmatis (strain ATCC $700084 / \mathrm{mc}(2) 155)$ OX=246196 GN=groL1 $P E=1 \mathrm{SV}=1$

Protein sequence coverage: $22 \%$

Matched peptides shown in bold red.

1 WAKTIAYDER ARRGLERGL SLADAVKVTL GPKGRRVVLE KRWGAPTIT: 51 DGVSIAKEIR LBDPYEKTGA ELVKEVAKKT DDVAGDOTTT ATVLAQALVF

101 EGLRNVAAGA NPLGLRRGIE KAVERVTETL LKSAREVETK EQTAATAGIS

151 AGDQSTGDLI AERMDRVGNE GVITVEESIT FGLQLELTEG MRFDRGYTSO

201 YFVTDARRQE AVLEDPYILL VSSKVSTVKD LLPLLEKVIQ SGKPLLIIAZ

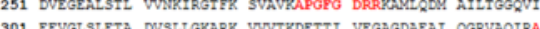

SOI LEVOLSLETA DWSLLOWRR WVIKDETH VEGAGDAEAT QGRVAQIRA

351 1 100

401 a

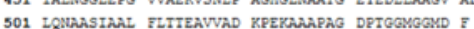



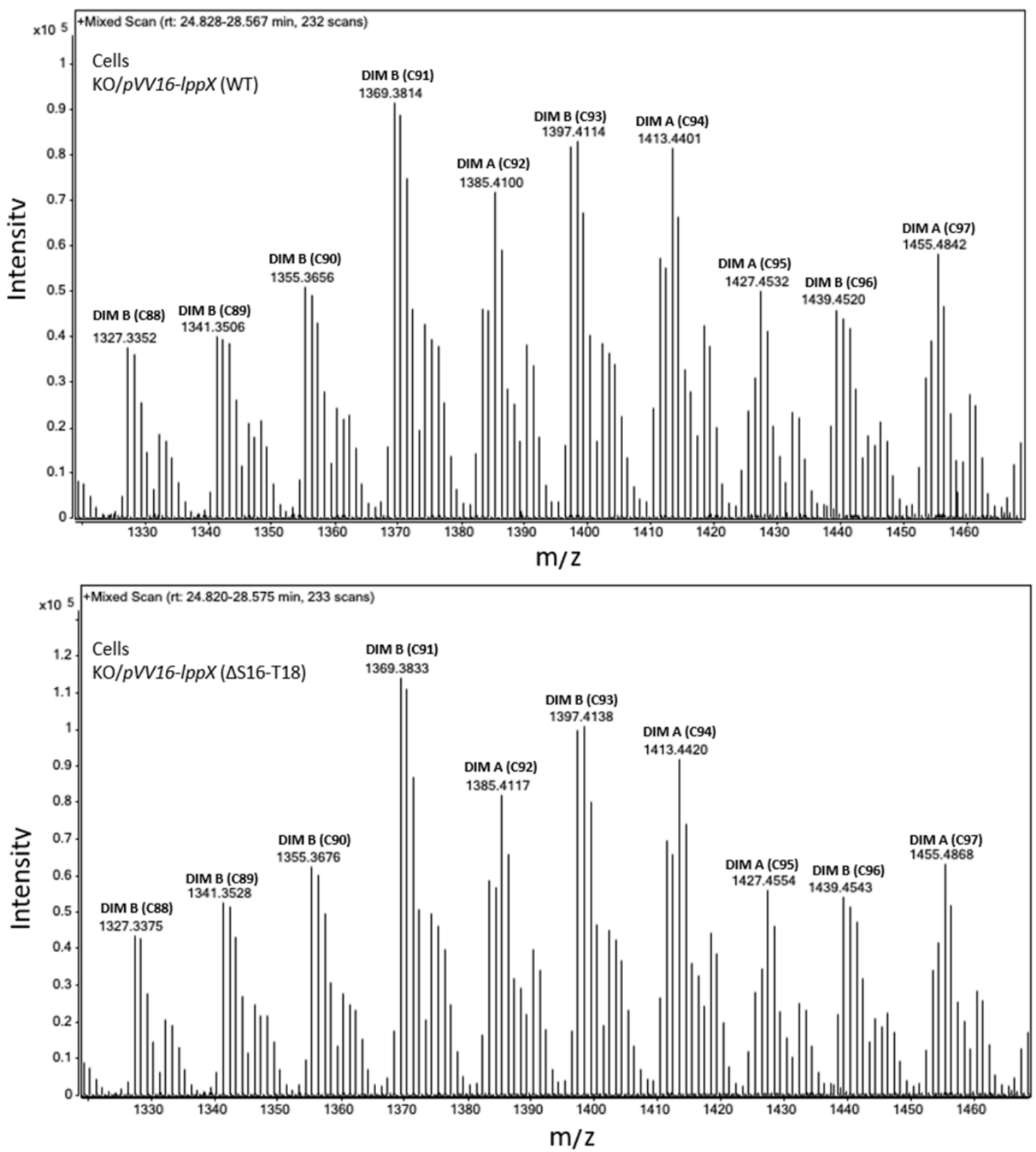

787 
M. bovis SIU01591.1 CSSPKPDAEEQGVPVSPTASDPALLAEIRQSLDATKGLTS

M. leprae WP_010907555.1 CSSTKPDAQEQSSSSSPASSDPALTAEIKQSLETTKALSS

M. marinum WP_094357885.1 CSSDKTQPEAQSSTTVPADPALMAEIEQSLDATKALTSAH

M. ulcerans WP_134427244.1 CSSDKTQPEAQSSTTVPADPALMAEIEQSLDATKALTSAH 790

M. gordonae WP_069434779.1 CASAPKESEAPPATGTTTDSPLMADVRQSVDATKALTSAH 